\title{
Simplification of the Mitsunobu Reaction. DCAD: A New Azodicarboxylate.
}

\author{
Bruce H. Lipshutz, ${ }^{*}$ David W. Chung, ${ }^{a}$ Brian Rich, and \\ Ricardo Corral \\ "Department of Chemistry and Biochemistry \\ University of California, Santa Barbara, CA 93106
}

\section{Supporting Information}

There were two errors in the version published September 29, 2006. On p S3, " $N$-Boc-2aziridinylbenzyl propionate (Table 1, entry 8)." should read: "Benzyl (2-tertbutoxycarbonylamino) propenoate (Table 1, entry 8)." Reference 6 should read: "Cherney, R. J.; Wang, L. J. Org. Chem. 1996, 61, 2544-2546." 
(R)-[2-(4-Nitrobenzoyl)oxy]-methylpropionate [6]. Following the General Procedure, 4nitrobenzoic acid (368 mg, $2.20 \mathrm{mmol}$ ) was coupled to methyl (S)-(-)-lactate (190 $\mu \mathrm{L}, 1.99$ mmol) using 3 (842 mg, $2.29 \mathrm{mmol}$ ) and triphenylphosphine (576 mg, $2.20 \mathrm{mmol}$ ). Filtration of the reaction mixture afforded the reduced azodicarboxylate 4 as a white powder (577 mg, $68 \mathrm{~mol}$ $\%$ recovery). Flash chromatography eluted with hexanes to 1:14 EtOAc/hexanes afforded the title compound as a yellow solid (446 mg, 88\%): $\mathrm{mp} 31-33^{\circ} \mathrm{C}$; $[\alpha]_{\mathrm{D}}{ }^{20}-19.4^{\circ}(\mathrm{c}=10.0 \mathrm{mg} / \mathrm{mL}$, $\mathrm{CHCl}_{3}$ ); IR (NaCl, neat): 3421, 1733, $1712 \mathrm{~cm}^{-1} ;{ }^{1} \mathrm{H} \mathrm{NMR}\left(\mathrm{CDCl}_{3}\right) \delta 8.33-8.25$ (m, 4H, ArH), $5.38\left(\mathrm{q}, J=7.2 \mathrm{~Hz}, \mathrm{CHCH}_{3}\right), 3.80\left(\mathrm{~s}, \mathrm{OCH}_{3}\right), 1.67\left(\mathrm{~d}, J=7.2 \mathrm{~Hz}, \mathrm{CHCH}_{3}\right) ;{ }^{13} \mathrm{C} \mathrm{NMR}\left(\mathrm{CDCl}_{3}\right)$ $\delta$ 170.92, 164.28, 150.95, 134.99, 131.22, 123.79, 70.03, 52.82, 17.24; HREIMS $\mathrm{m} / \mathrm{z}$ calcd. for $\mathrm{C}_{11} \mathrm{H}_{11} \mathrm{NO}_{6}$ : $253.0586(\mathrm{M})^{+}$, found: 253.0592.

( \pm )-Glycidyl-4-nitrobenzoate [7]. Following the General Procedure, 4-nitrobenzoic acid (360 mg, $2.15 \mathrm{mmol}$ ) was coupled to ( \pm )-glycidol (130 $\mu$ l, $1.96 \mathrm{mmol})$ using 3 (794 mg, $2.16 \mathrm{mmol}$ ) and triphenylphosphine (567 mg, $2.16 \mathrm{mmol}$ ). Filtration of the reaction mixture afforded the reduced azodicarboxylate 4 as a white powder (630 mg, 79 mol \% recovery). Flash chromatography eluted with 1:19 EtOAc/hexanes to 1:6 EtOAc/hexanes afforded the title compound as a light yellow powder (429 mg, 98\%). The spectral data matched that provided in the literature. ${ }^{1}$

1-Bromo-4-[(R)-1-methylheptyloxy]benzene [8]. Following the General Procedure, 4bromophenol (385 mg, $2.22 \mathrm{mmol}$ ) was coupled to (S)-2-octanol (320 $\mu \mathrm{L}, 2.02 \mathrm{mmol}$ ) using 3 (856 mg, $2.33 \mathrm{mmol}$ ) and triphenylphosphine (583 mg, $2.22 \mathrm{mmol})$. Filtration of the reaction mixture afforded the reduced azodicarboxylate 4 as a white powder (565 mg, $66 \mathrm{~mol} \%$ recovery). Flash chromatography eluted with hexanes afforded the title compound as a colorless oil (445 mg, 77\%): $[\alpha]_{\mathrm{D}}^{20}-8.2^{\circ}\left(\mathrm{c}=10.7 \mathrm{mg} / \mathrm{mL}, \mathrm{CHCl}_{3}\right.$ ). The spectral data matched that provided in the literature. ${ }^{2}$

2-Methylchroman (Table 1, entry 4). Following the General Procedure, cyclization of $o$-(2hydroxybutyl)phenol (348 mg, $2.01 \mathrm{mmol})$ using 3 (850 mg, $2.31 \mathrm{mmol}$ ) and triphenylphosphine (580 mg, $2.21 \mathrm{mmol}$ ). Filtration of the reaction mixture afforded the reduced azodicarboxylate 4 as a white powder (573 mg, $67 \mathrm{~mol} \%$ recovery). Flash chromatography eluted with hexanes afforded the title compound as a colorless liquid (269 mg, 90\%). The product is volatile! The spectral data matched that provided in the literature. ${ }^{3}$

(R)-2-Methylheptyl phthalimide [9]. Following the General Procedure, phthalimide (328 mg, $2.23 \mathrm{mmol}$ ) was coupled to (S)-2-octanol (320 $\mu \mathrm{L}, 2.02 \mathrm{mmol})$ using 3 (855 mg, $2.33 \mathrm{mmol}$ ) and triphenylphosphine (584 mg, $2.23 \mathrm{mmol}$ ). Filtration of the reaction mixture afforded the reduced azodicarboxylate 4 as a white powder (624 mg, $72 \mathrm{~mol} \%$ recovery). Flash chromatography eluted with hexanes to 1:19 EtOAc/hexanes afforded the title compound as a light yellow oil (417 mg, 80\%): $[\alpha]_{\mathrm{D}}{ }^{20}-15.8^{\circ}\left(\mathrm{c}=16.2 \mathrm{mg} / \mathrm{mL}, \mathrm{CHCl}_{3}\right.$ ). The spectral data matched that provided in the literature. ${ }^{4}$

Retinyl phthalimide [10]. Following the General Procedure, phthalimide (308 mg, $2.09 \mathrm{mmol}$ ) was coupled to retinol (571 mg, $1.99 \mathrm{mmol}$ ) using 3 (806 mg, $2.20 \mathrm{mmol}$ ) and triphenylphosphine (548 mg, $2.09 \mathrm{mmol})$. Filtration of the reaction mixture afforded the reduced azodicarboxylate 4 as a white powder. Flash chromatography eluted with hexanes to 1:4 
EtOAc/hexanes afforded the title compound as a yellow oil (277 mg, 33\%), mixture of $\mathrm{S}_{\mathrm{N}} 2$ and $\mathrm{S}_{\mathrm{N}} 2$ ' regioisomers: IR ( $\mathrm{NaCl}$, neat): 3466, 1712, $1611 \mathrm{~cm}^{-1} ;{ }^{1} \mathrm{H} \mathrm{NMR}\left(\mathrm{CDC1}_{3}\right) \delta 7.82,7.79$ (dd, $J=2.8,5.2 \mathrm{~Hz}$, dd, $J=2.8,5.2 \mathrm{~Hz}, 2 \mathrm{H}$ total), 7.70 (dd, $J=2.8 \mathrm{~Hz}, 5.2 \mathrm{~Hz}, 2 \mathrm{H}), 6.59-6.34$ (m, 2H), 6.18-5.92 (m, 4H), 5.22 (dd, $J=10.0,17.2 \mathrm{~Hz}, 1 \mathrm{H}$ ), 5.05 (dd, 10.8, $15.2 \mathrm{~Hz}, 1 \mathrm{H}), 2.03,1.98$ (t, $J=6.4 \mathrm{~Hz}, \mathrm{t}, J=7.2 \mathrm{~Hz}, 2 \mathrm{H}$ total), $1.94(\mathrm{~s}, 2 \mathrm{H}), 1.90(\mathrm{~m}, 3 \mathrm{H}), 1.84(\mathrm{~d}, J=4.0 \mathrm{~Hz}, 1 \mathrm{H}), 1.75$ (s, 1H), 1.72, 1.70 (s, s, $1 \mathrm{H}$ total), 1.66 (s, 2H), 1.62-1.55 (m, 3H), 1.47-1.40 (m, 2H), 1.31-1.26 (m, 2H), $1.14(\mathrm{~s}, 1 \mathrm{H}), 1.10(\mathrm{~s}, 1 \mathrm{H}), 1.01-0.96(\mathrm{~m}, 4 \mathrm{H}), 0.90-0.84(\mathrm{~m}, 1 \mathrm{H}) ;{ }^{13} \mathrm{C} \mathrm{NMR}\left(\mathrm{CDCl}_{3}\right) \delta$ 167.89, 140.80, 137.58, 137.06, 136.86, 136.60, 134.05, 132.34, 129.42, 128.86, 127.84, 126.44, 123.39, 114.00, 46.85, 39.71, 34.37, 33.10, 29.08, 28.89, 21.88, 19.43, 12.90, 12.33; HREIMS $\mathrm{m} / \mathrm{z}$ calcd. for $\mathrm{C}_{28} \mathrm{H}_{33} \mathrm{NO}_{2}$ : $415.2511(\mathrm{M})^{+}$, found: 415.2526 .

Geranyl succinimide (Table 1, entry 7). Following the General Procedure, succinimide (218 mg, $2.20 \mathrm{mmol}$ ) was coupled to geraniol (350 $\mu \mathrm{l}, 1.99 \mathrm{mmol}$ ) using 3 (849 mg, $2.31 \mathrm{mmol}$ ) and triphenylphosphine (576 mg, $2.20 \mathrm{mmol}$ ). Filtration of the reaction mixture afforded the reduced azodicarboxylate 4 as a white powder (578 mg, $68 \mathrm{~mol} \%$ recovery). Flash chromatography eluted with 1:19 EtOAc/hexanes to 1:6 EtOAc/hexanes afforded the title compound as a colorless oil (347 mg, 74\%). The spectral data matched that provided in the literature. ${ }^{5}$

N-Boc-2-aziridinylbenzyl propionate (Table 1, entry 8). Following the General Procedure, cyclization of $\mathrm{N}$-Boc-2-amino-3-hydroxybenzyl propionate (591 mg, $2.00 \mathrm{mmol}$ ) using 3 (881 $\mathrm{mg}, 2.40 \mathrm{mmol}$ ) and triphenylphosphine $(592 \mathrm{mg}, 2.20 \mathrm{mmol})$. Filtration of the reaction mixture afforded the reduced azodicarboxylate 4 as a white powder (641 mg, $72 \mathrm{~mol} \%$ recovery). Flash chromatography eluted with hexanes to 1:19 EtOAc/hexanes afforded the title compound as a clear oil with a light yellow tint (488 mg, 88\%). The spectral data matched that provided in the literature. $^{6}$

1-Phenyl-5-(2-propynylthio)-1H-tetrazole [12]. Following the General Procedure, 1-phenyl1H-tetrazole-5-thiol, 11, (404 mg, $2.27 \mathrm{mmol})$ was coupled to propargyl alcohol (120 $\mu \mathrm{L}, 2.06$ $\mathrm{mmol}$ ) using 3 (871 mg, $2.37 \mathrm{mmol}$ ) and triphenylphosphine (594 mg, $2.26 \mathrm{mmol}$ ). Filtration of the reaction mixture afforded the reduced azodicarboxylate 4 as a white powder $(677 \mathrm{mg}, 77 \mathrm{~mol}$ \% recovery). Flash chromatography eluted with 1:19 EtOAc/hexanes to 1:14 EtOAc/hexanes afforded the title compound as a white powder (444 mg, quantitative yield). The spectral data matched that provided in the literature. ${ }^{7}$

\section{References}

1) Stamatov, S. D.; Stawinski, J. Tetrahedron. 2005, 61, 3659-3669.

2) Artal, M. C.; Toyne, K. J.; Goodby, J. W.; Barberá, J.; Photinos, D. J. J. Mater. Chem. 2001, 11, 2801-2807.

3) Aristoff, P. A.; Harrison, A. W.; Huber, A. M. Tetrahedron Lett. 1984, 25, 3955-3958.

4) Mitsunobu, O.; Wada, M.; Sano, T. J. Am. Chem. Soc. 1972, 94, 679-680.

5) Vig, O. P.; Trehan, I. R.; Kad, G. L.; Kumari, S.; Bedi, A. L. J. Indian Chem. Soc. 1985, 62, 238-240.

6) Cardillo, G.; Gentilucci, L; Gianotti, M; Tolomelli, A. Synlett. 2000, 9, 1309-1311.

7) Takeda, K.; Tsuboyama, K.; Torii, K.; Murata, M.; Ogura, H. Tetrahedron Lett. 1988, 29, 4105-4108. 


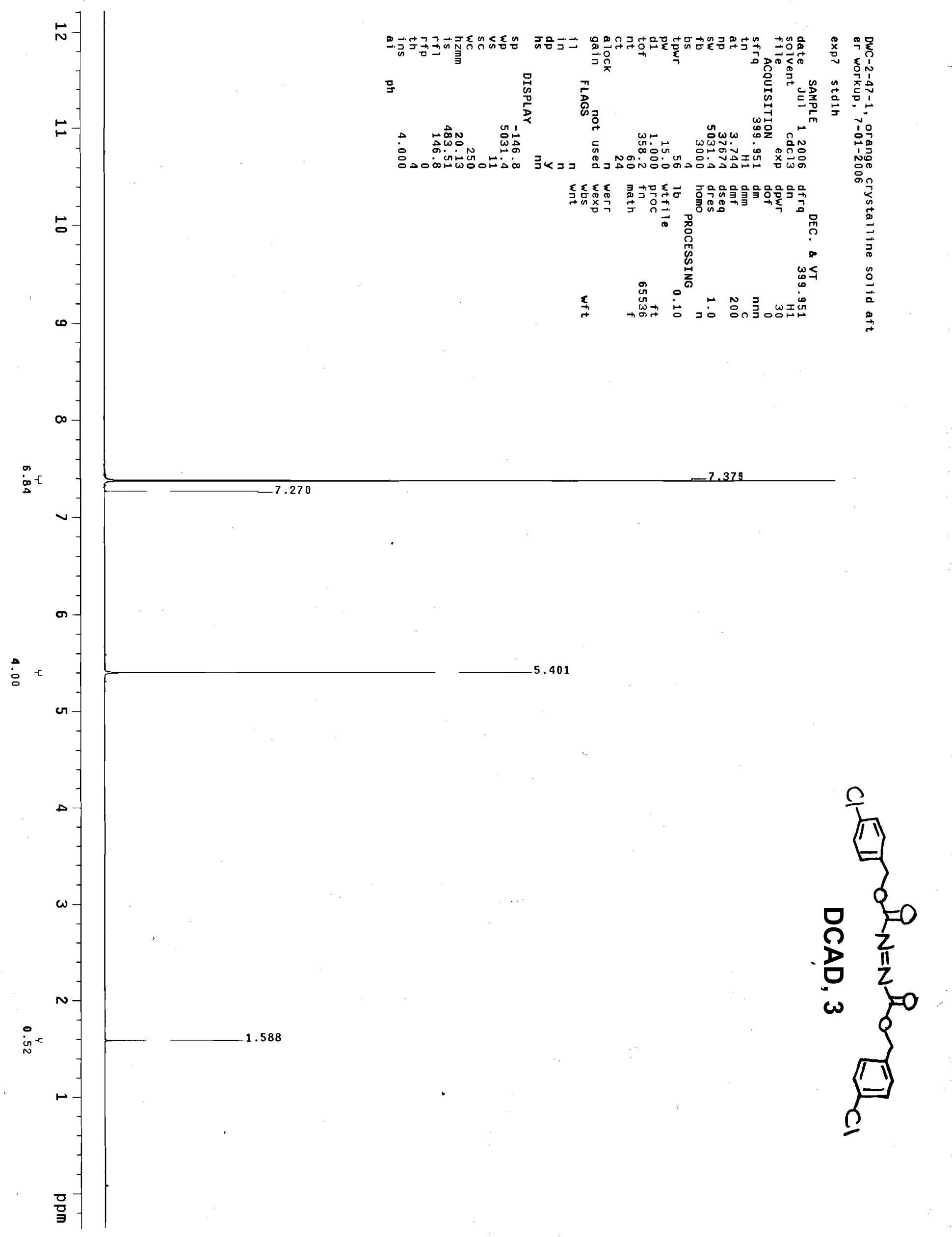




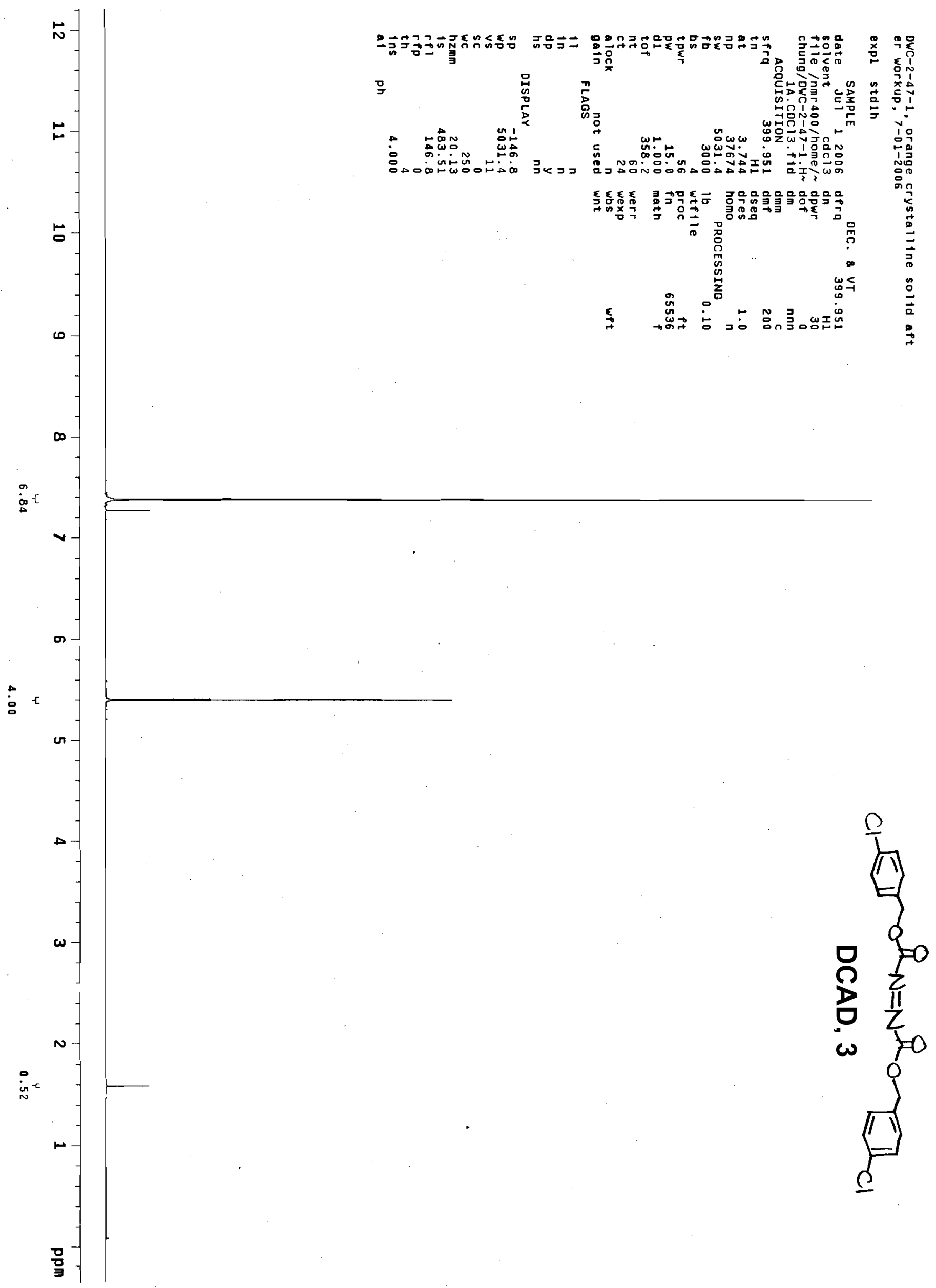




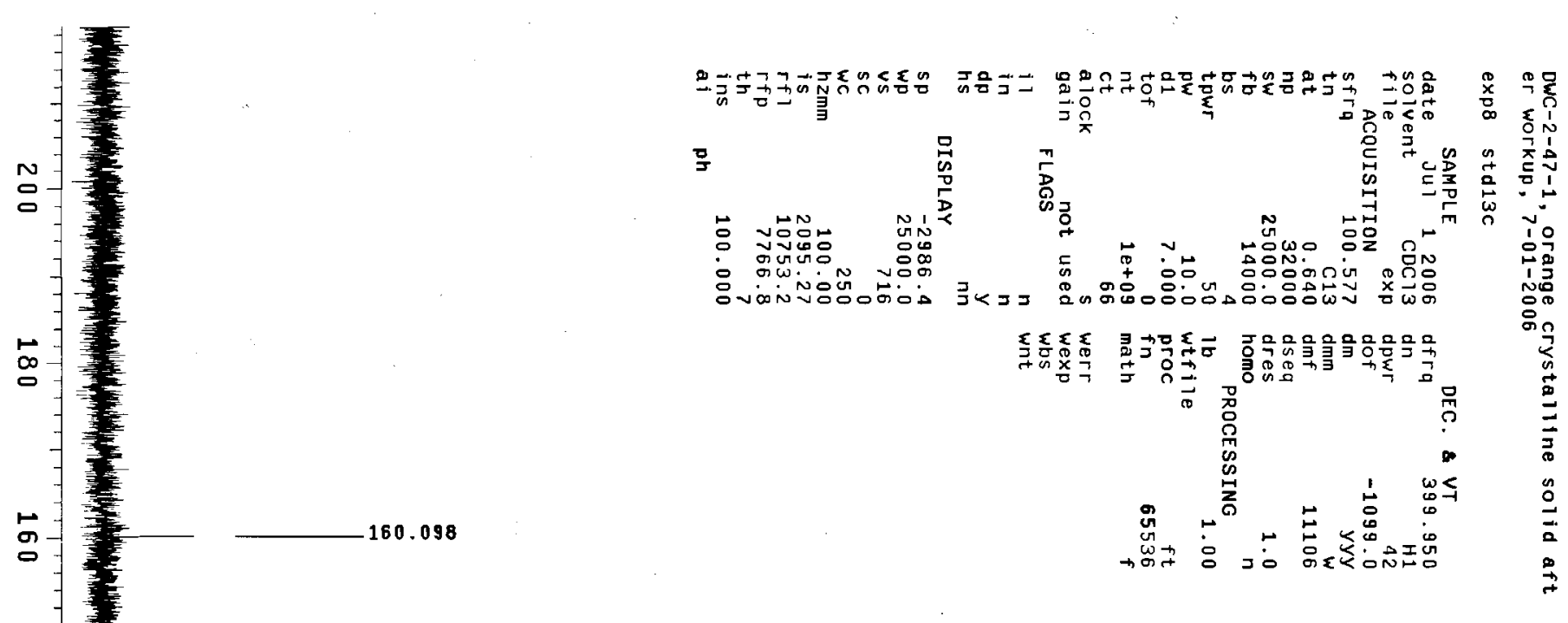

点-

동

$\infty$
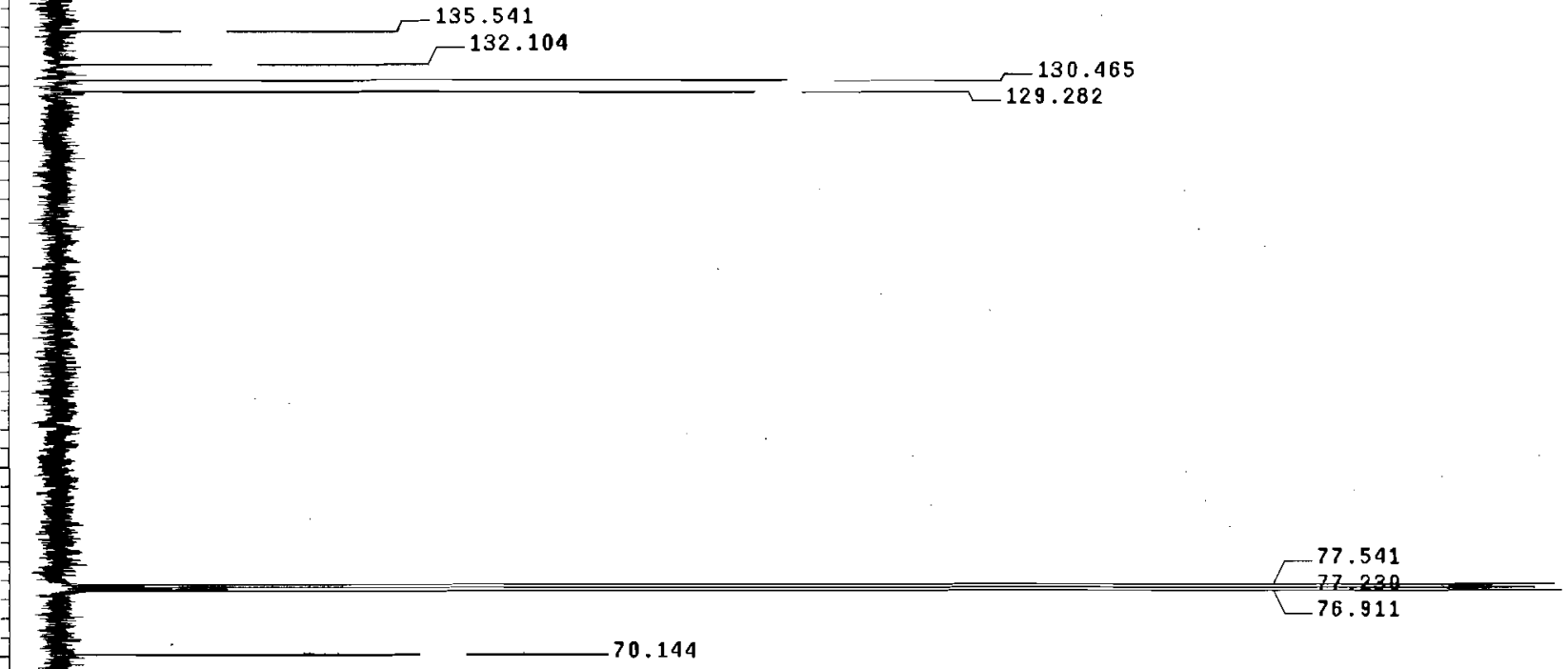

a

-

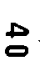

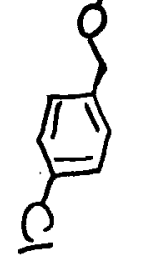




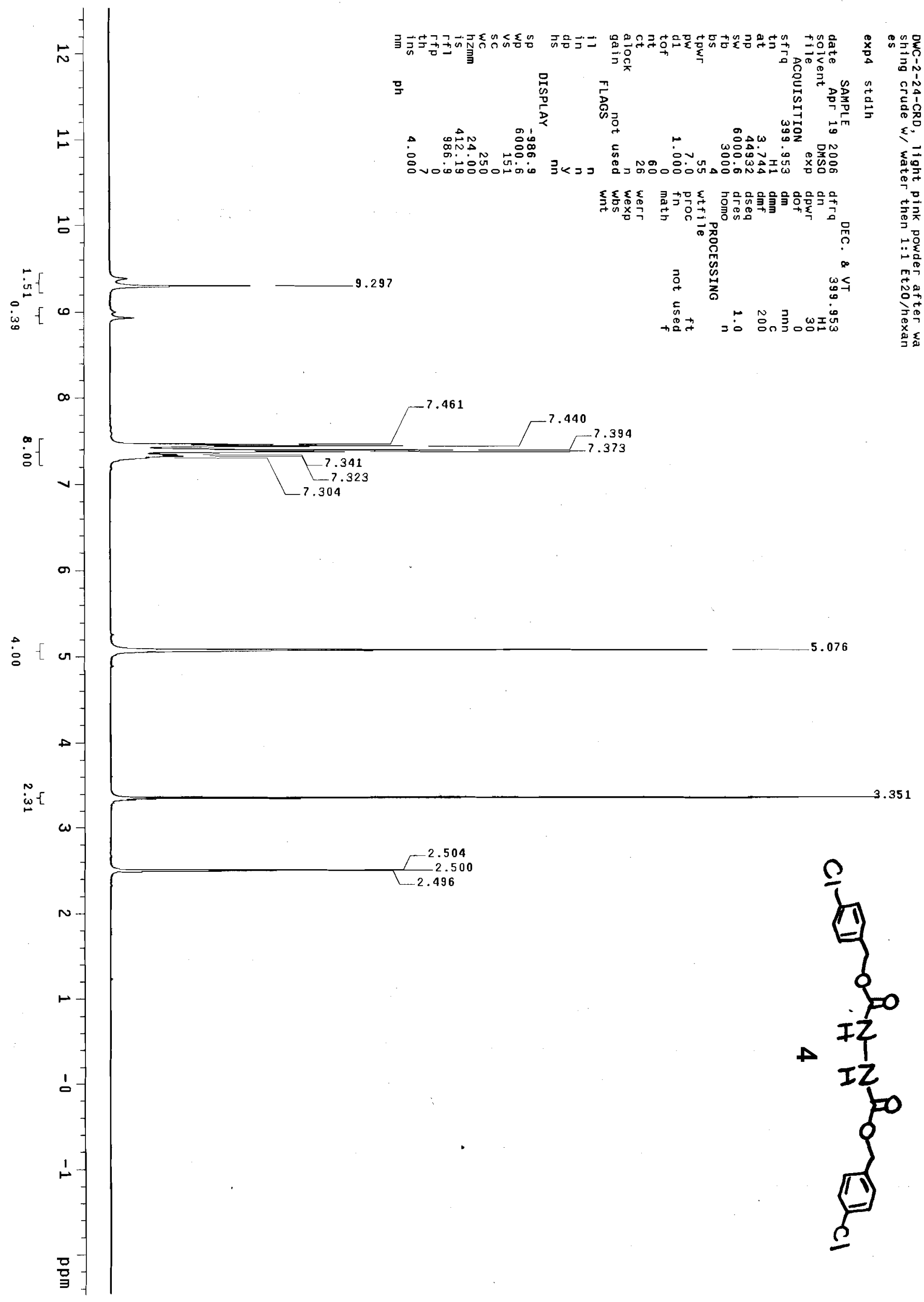




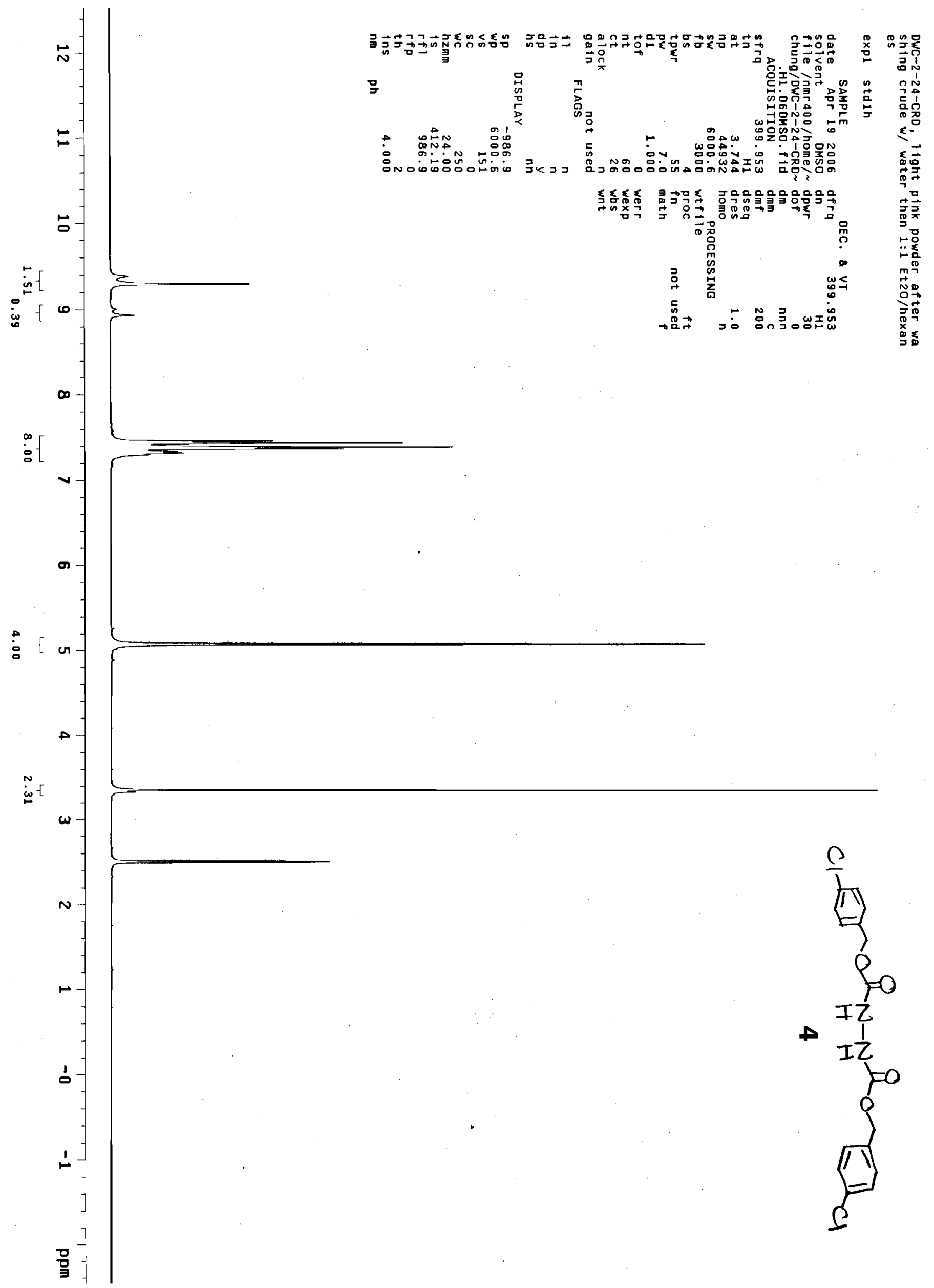




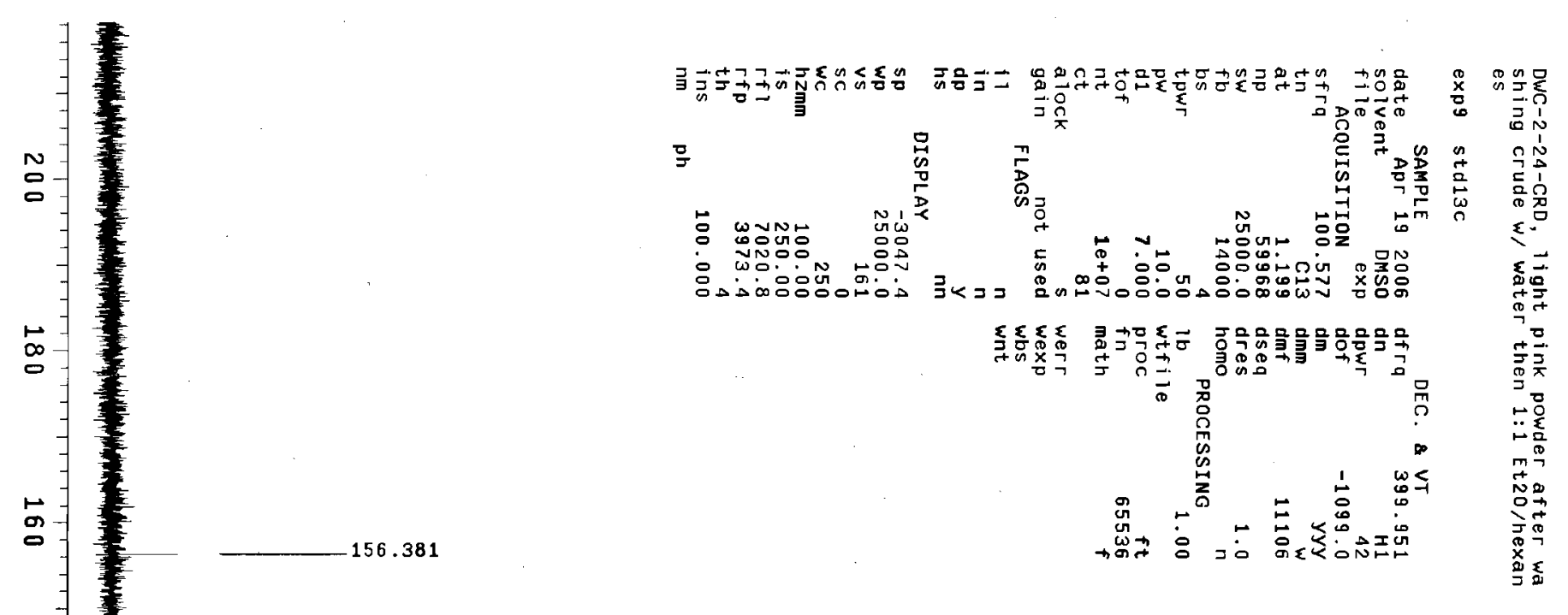

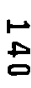

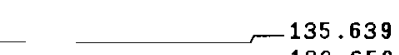

129.767

긍

믕-

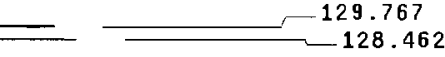

$\circ$

65.160

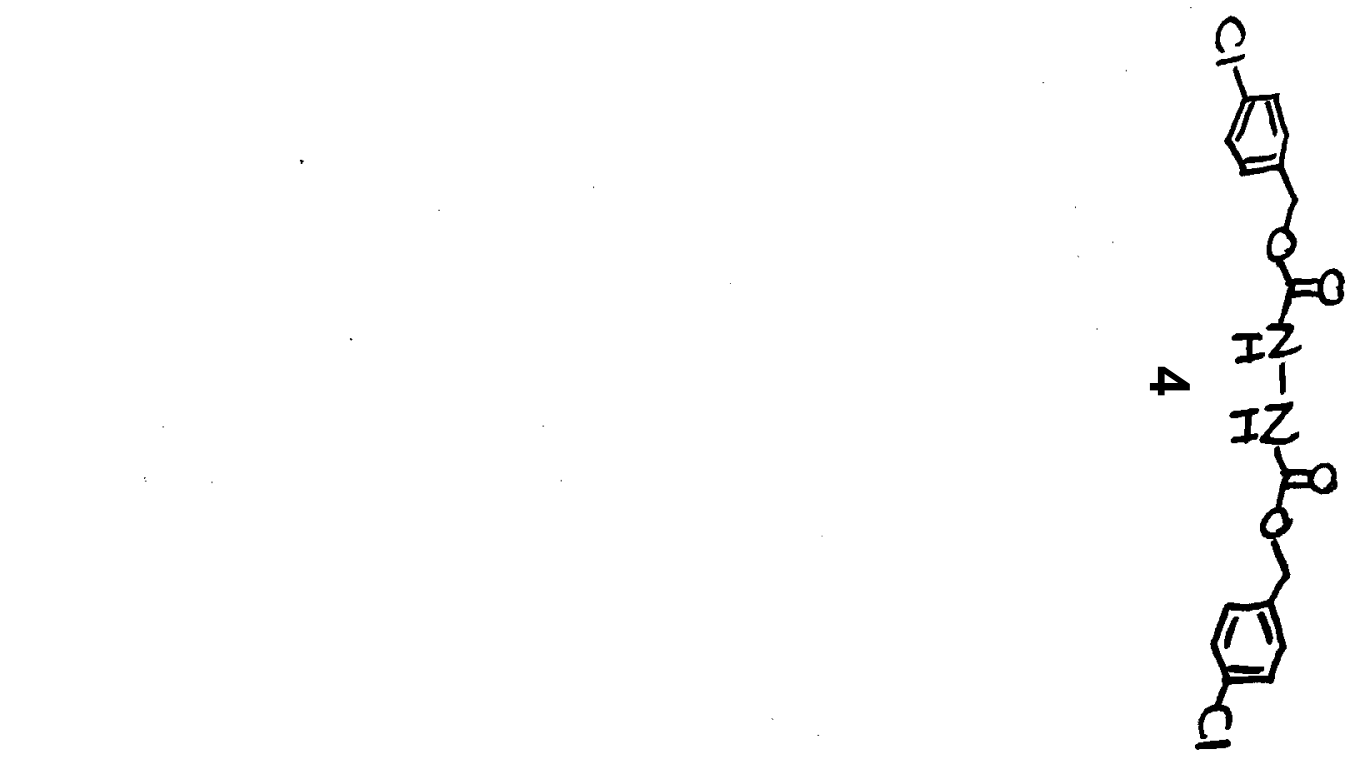

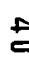

N

$\circ$

$-40.140$

-

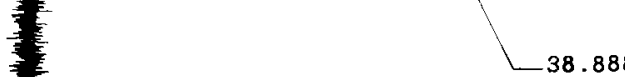

39.927

39.510
39.305

39.305 


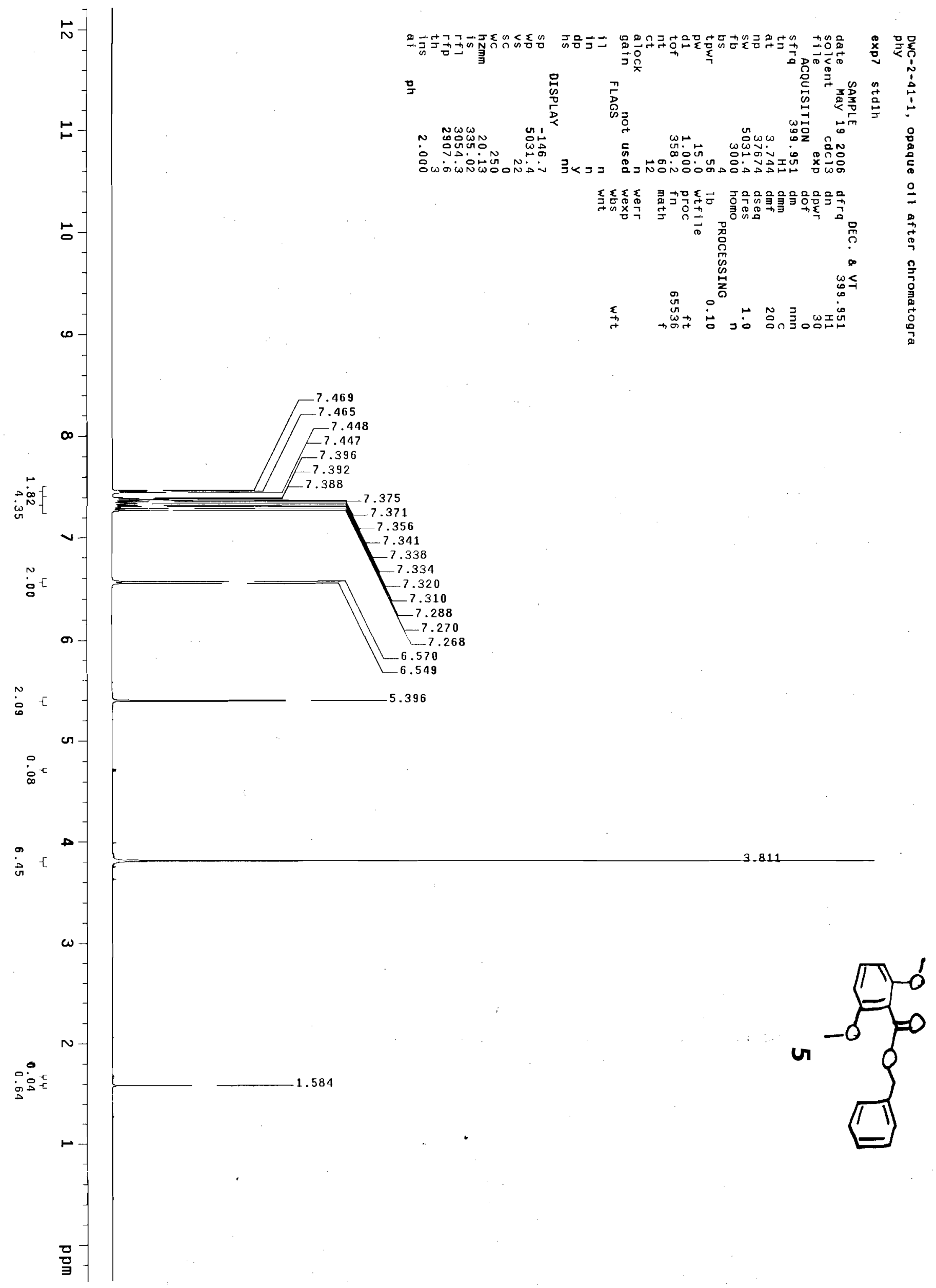




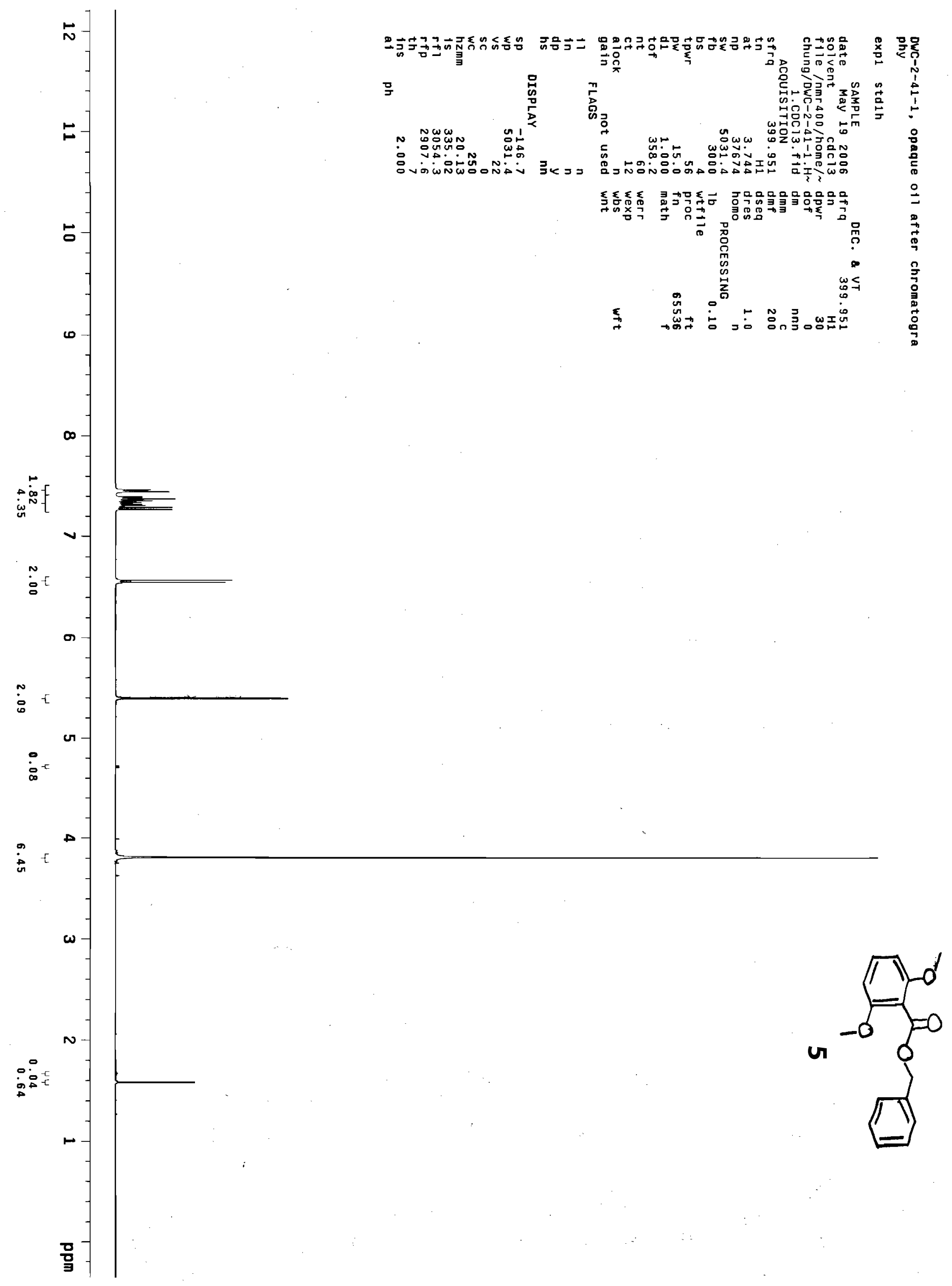




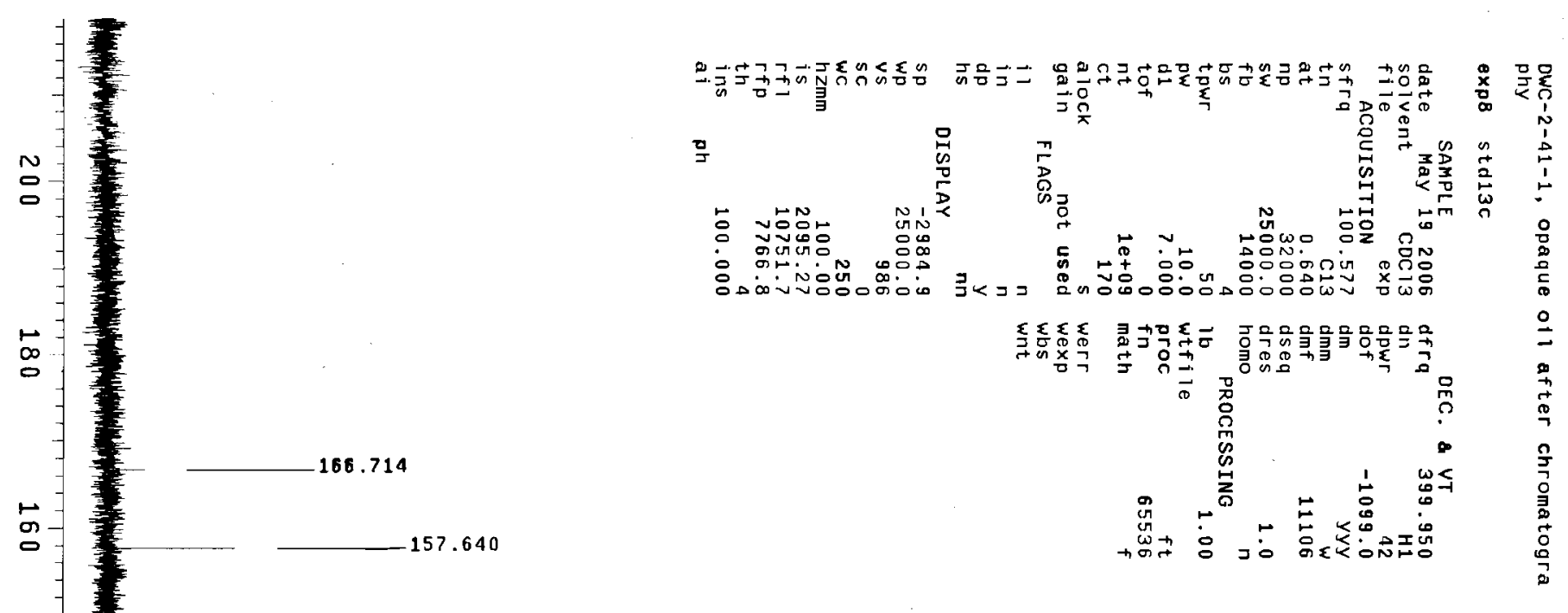

$-113.153$ 104.124

吕

$\stackrel{\infty}{\circ}$

E.

$\stackrel{5}{\circ}$ $-136.292$
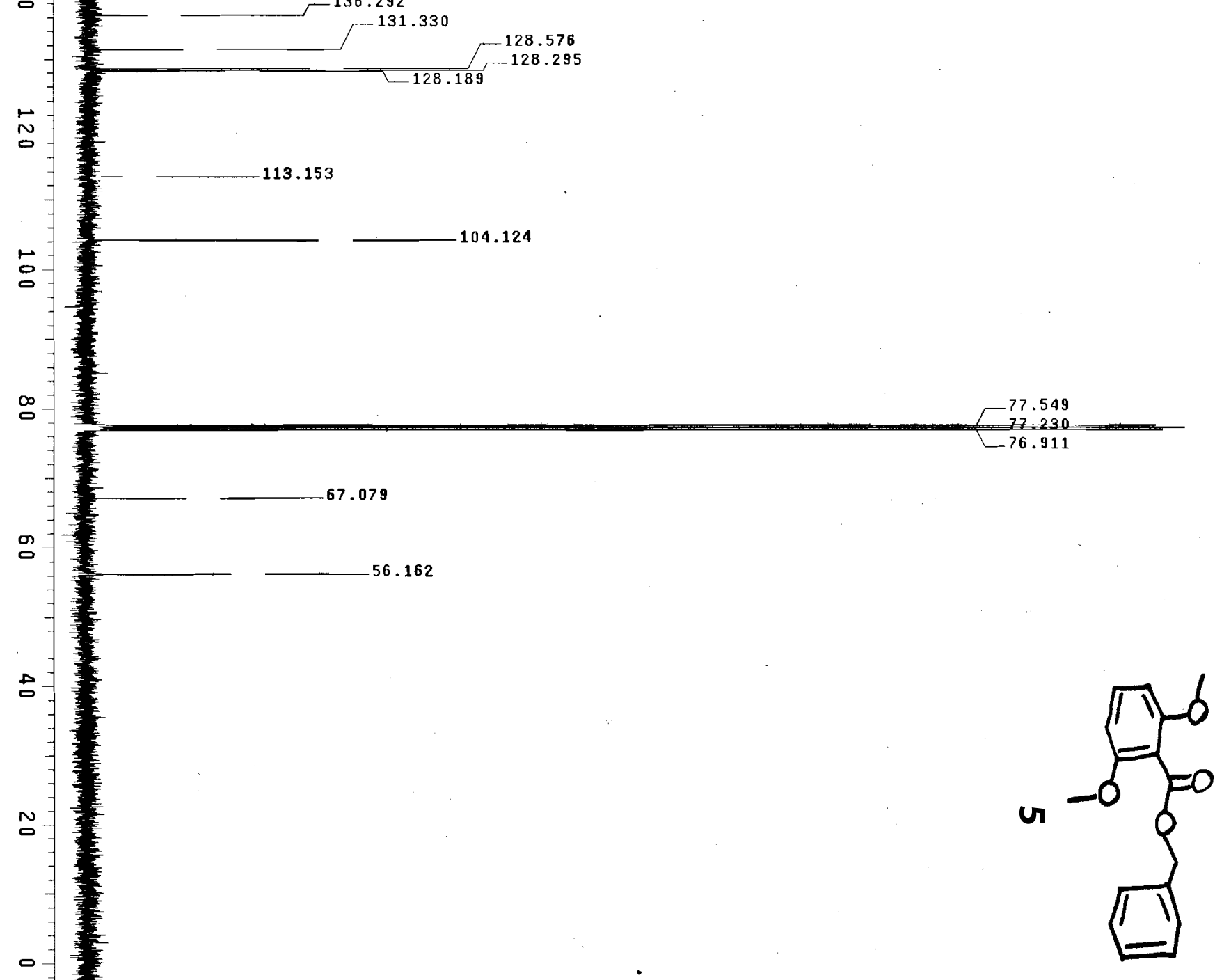

: 


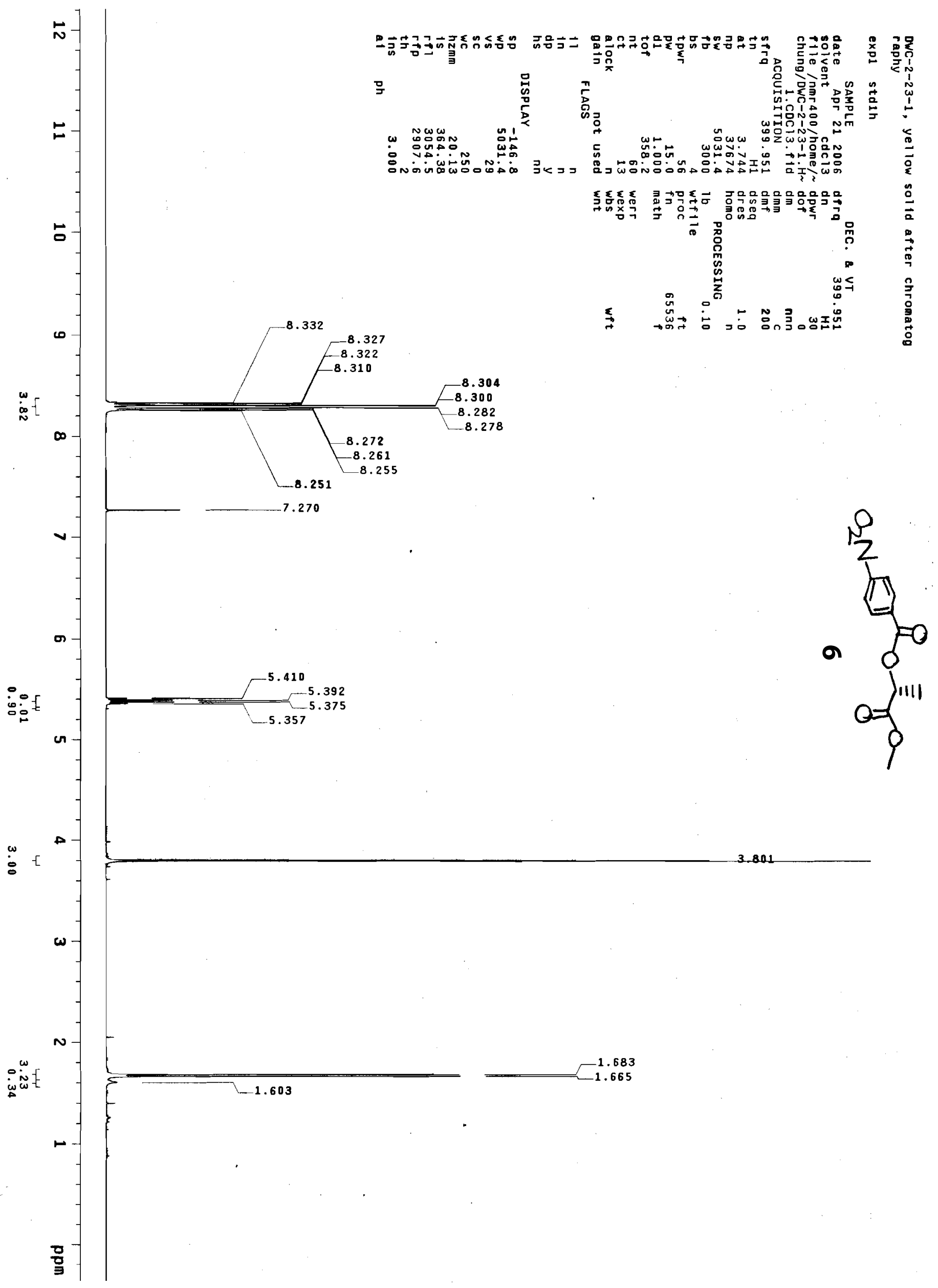




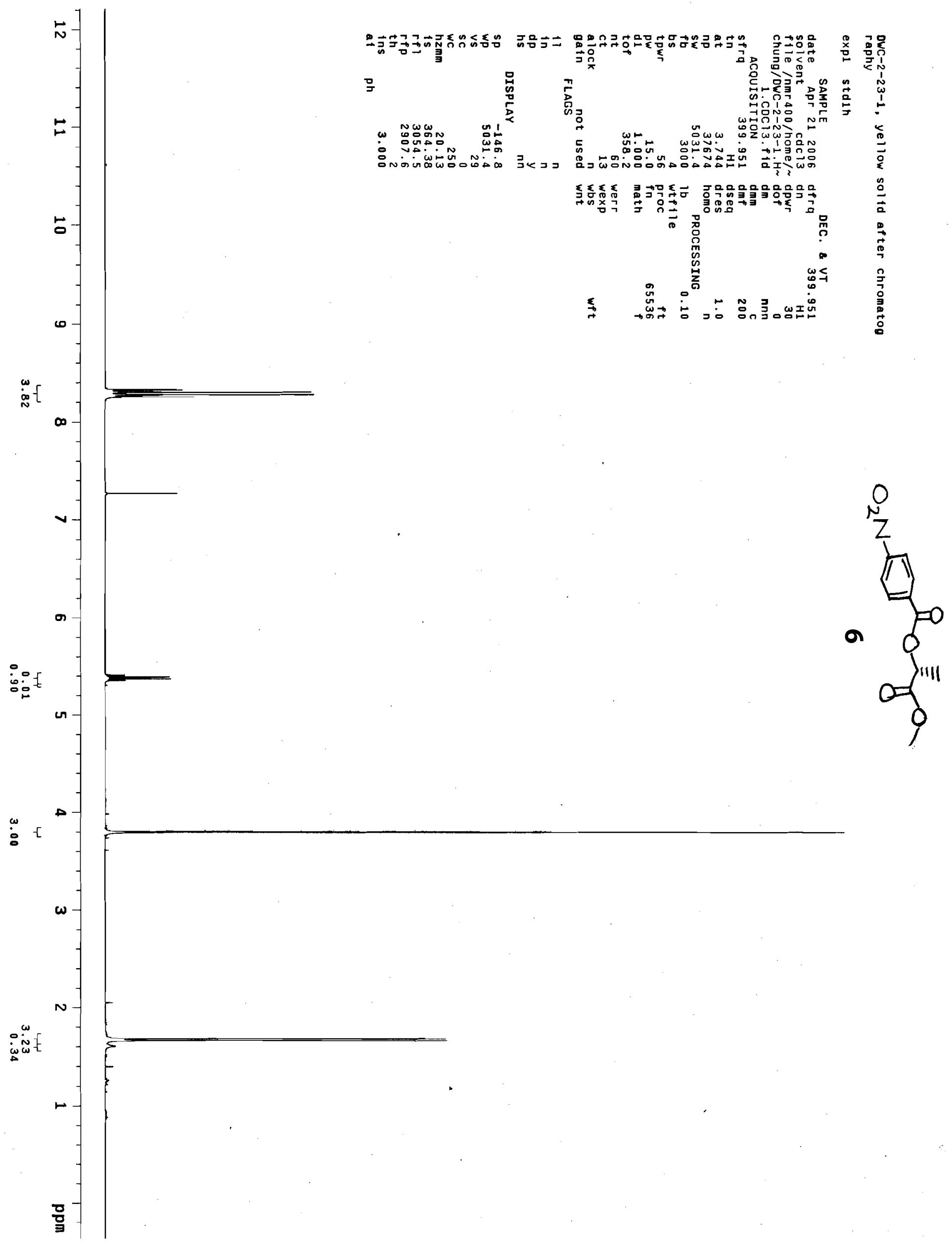



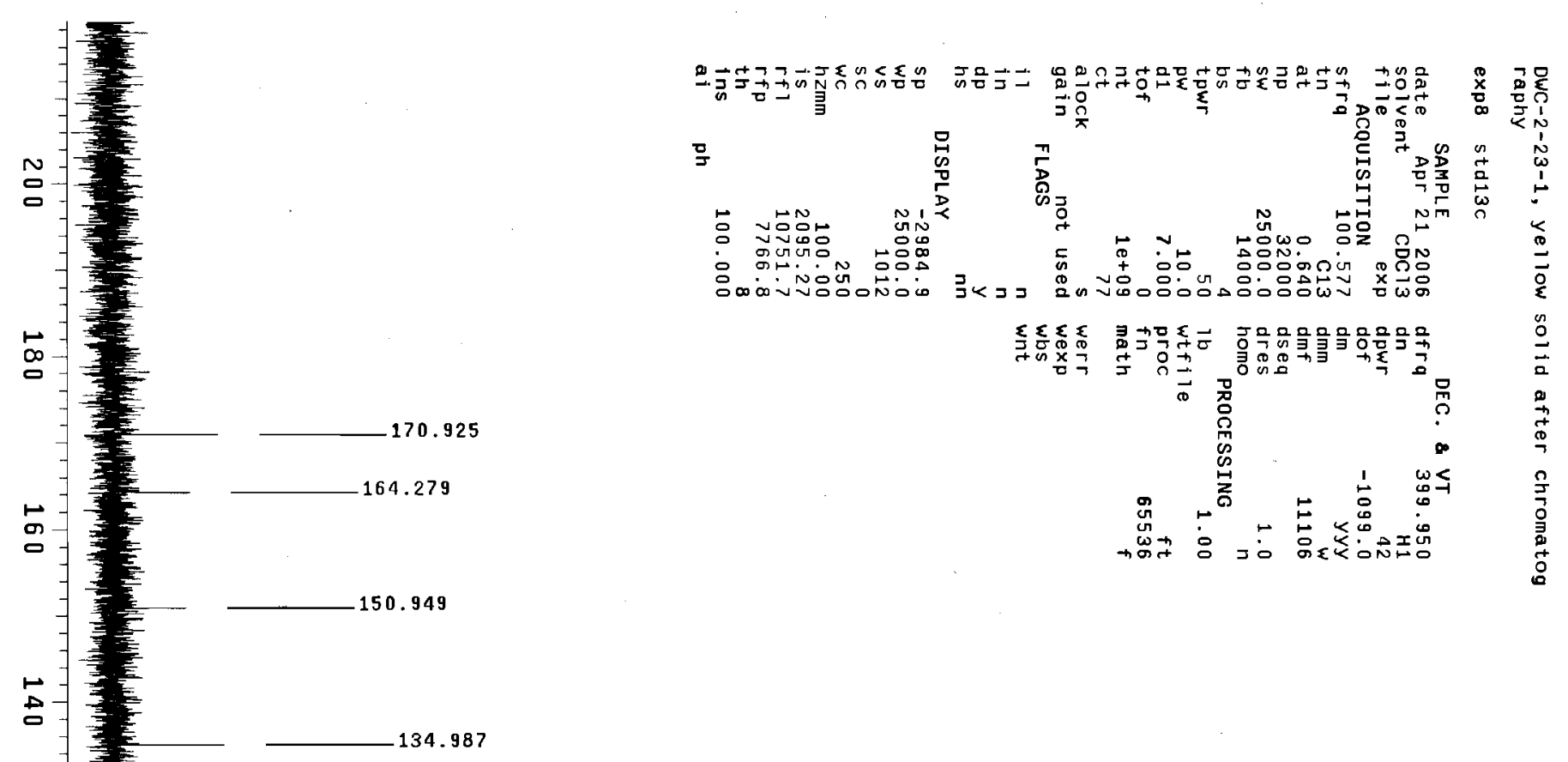

$-131.224$

No

$\infty$

๖

은

52.816

$\stackrel{\circ}{\circ}$

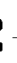

욤
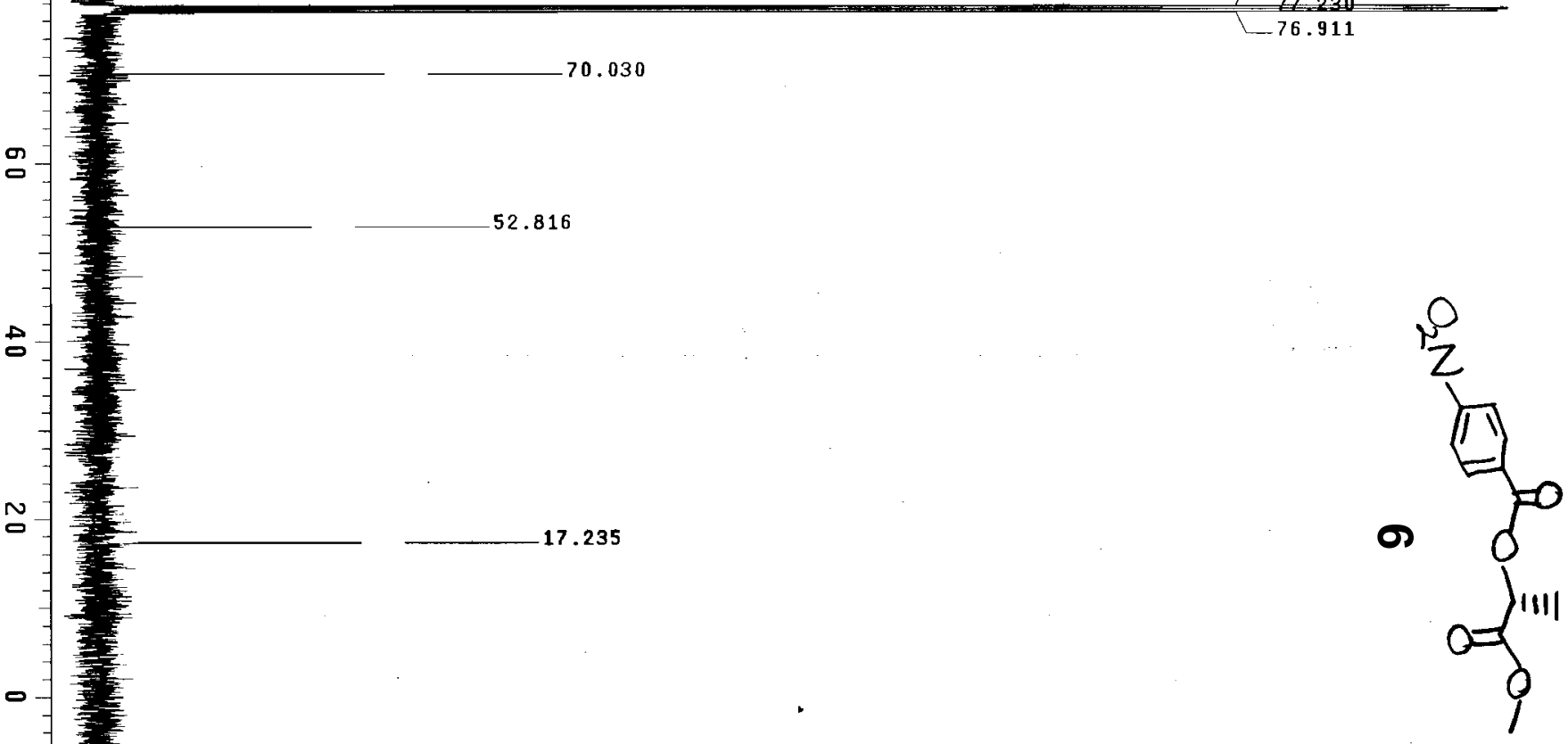

믘

70.030

$-77.230$ 77.230
-76.911 


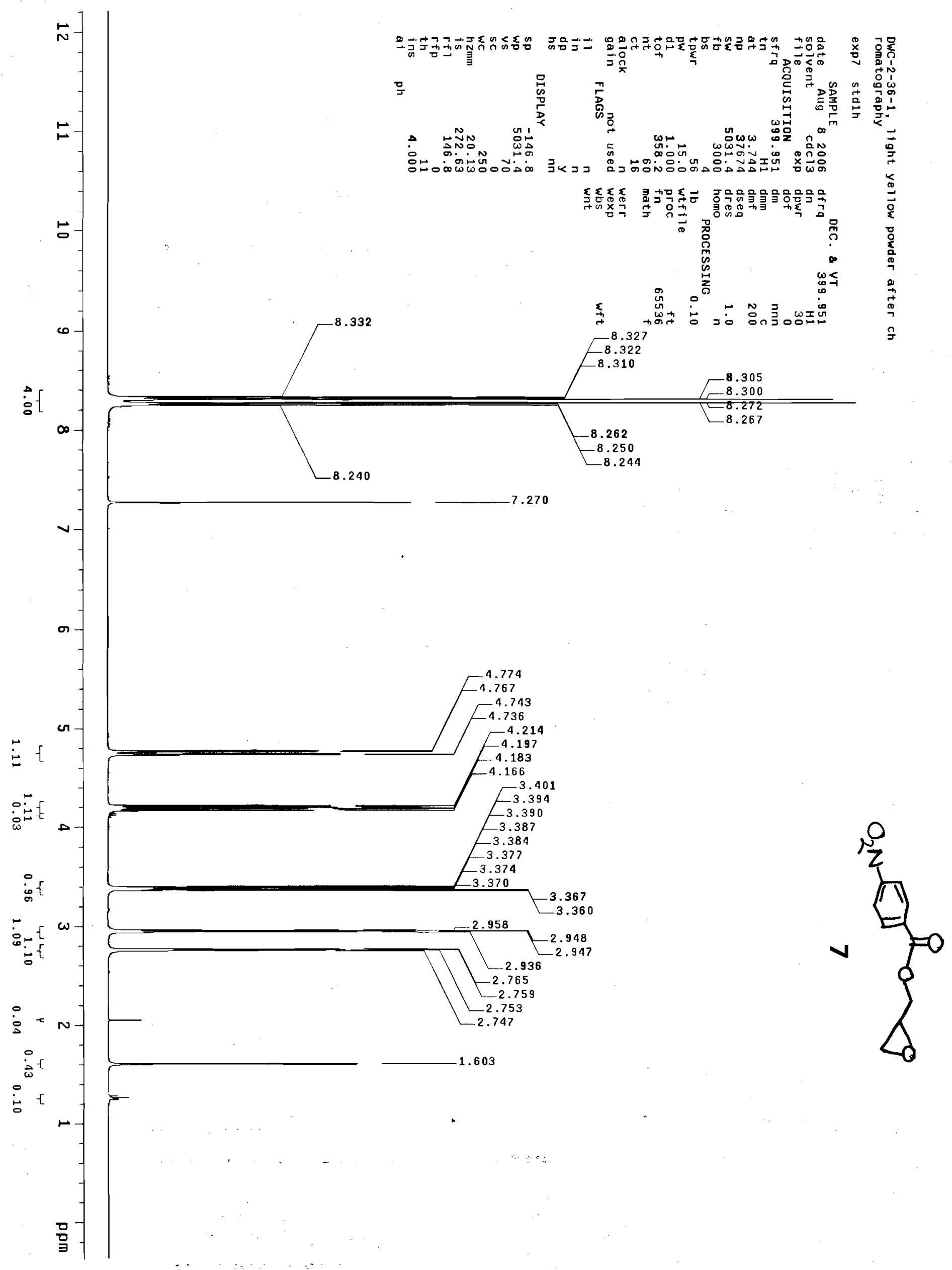

S16 


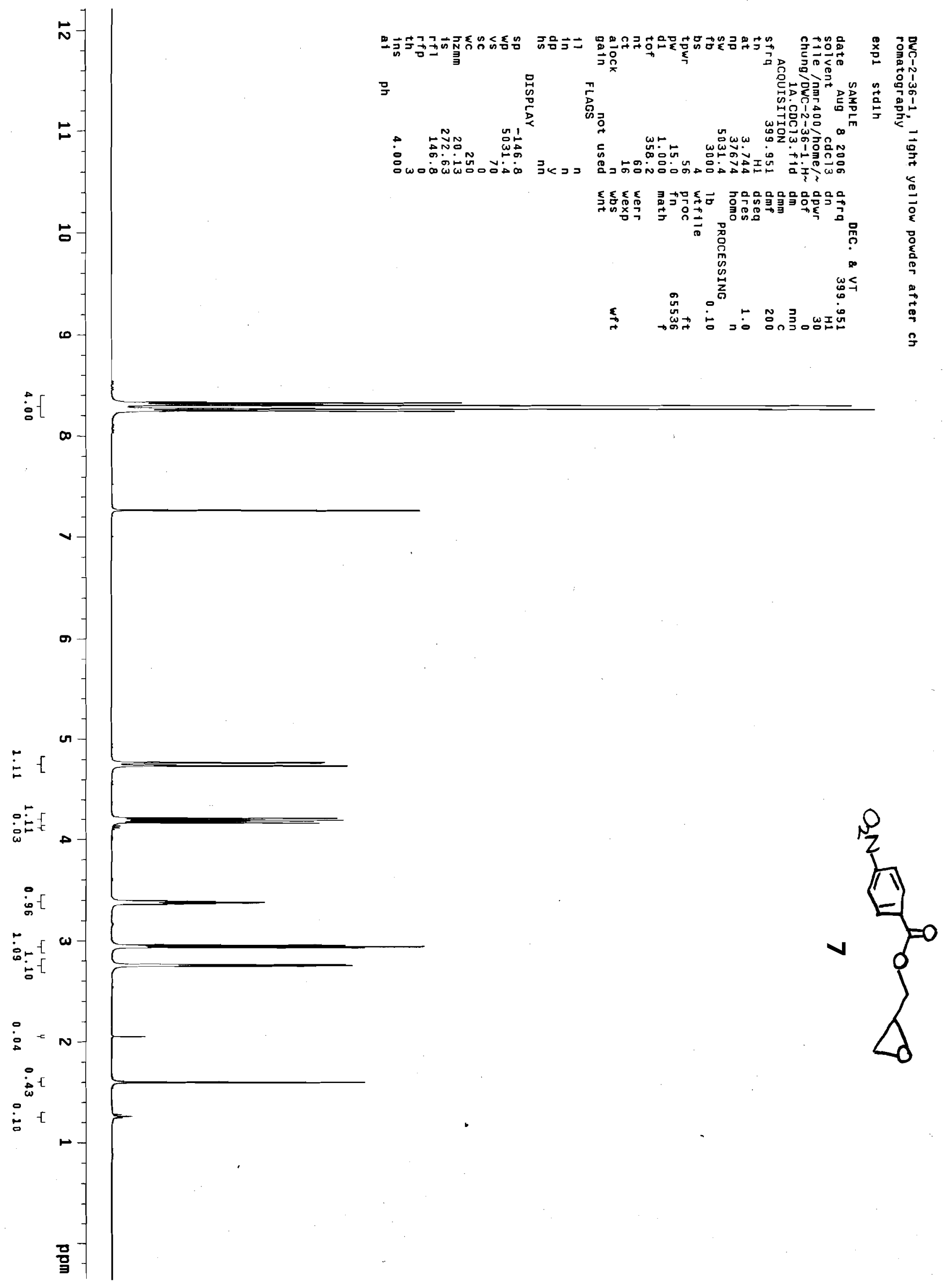




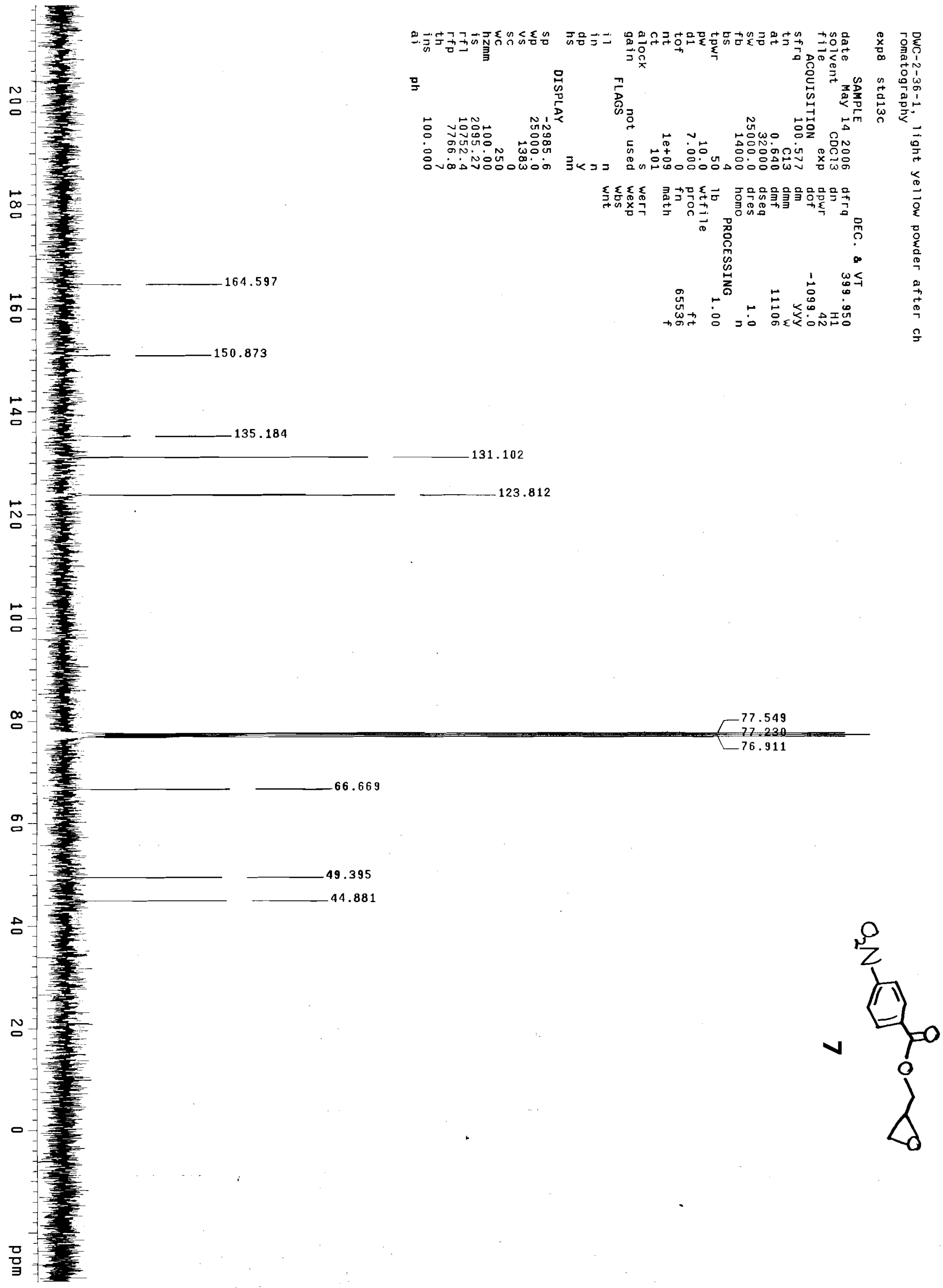




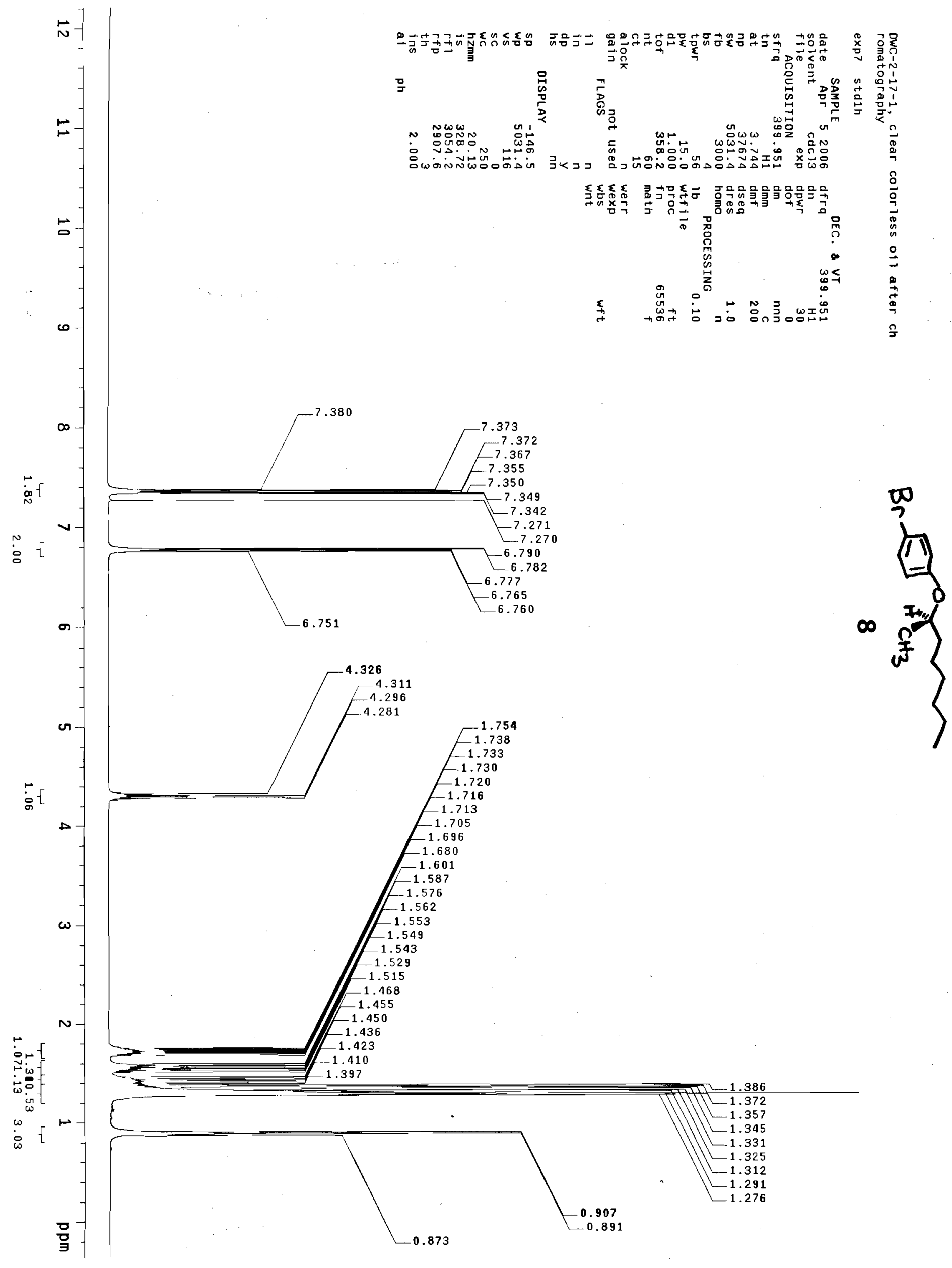




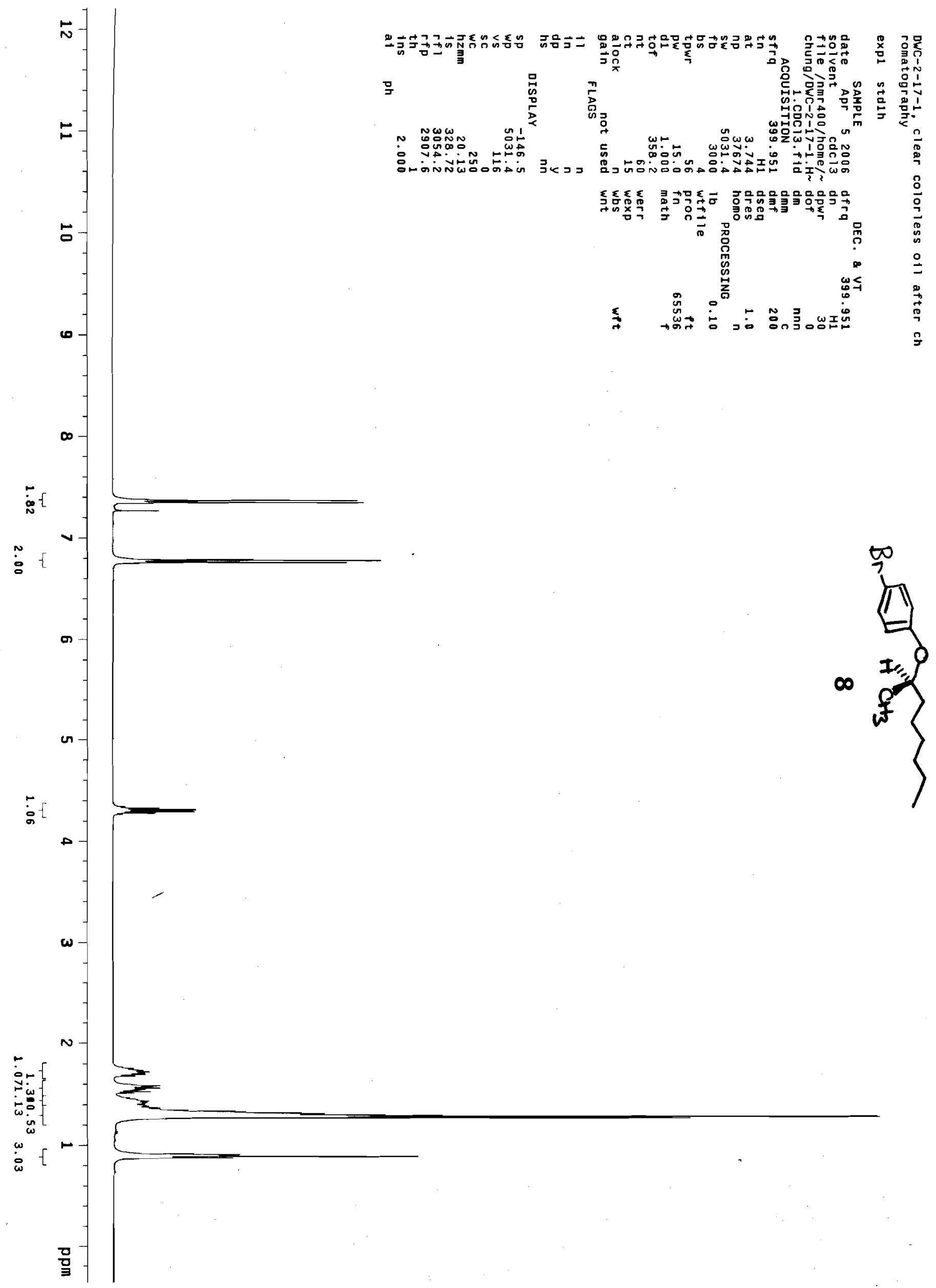




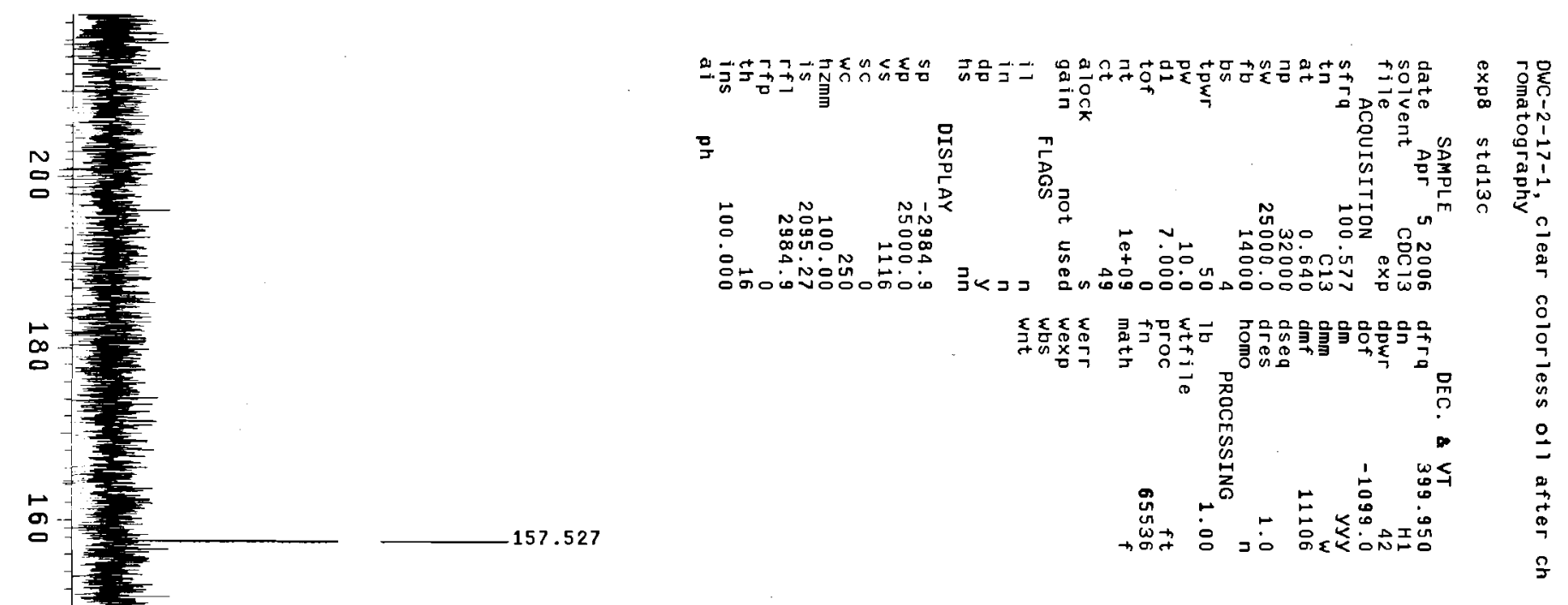

132.453

$\stackrel{\circ}{\sim}$

$\stackrel{\leftrightarrow}{\circ}$
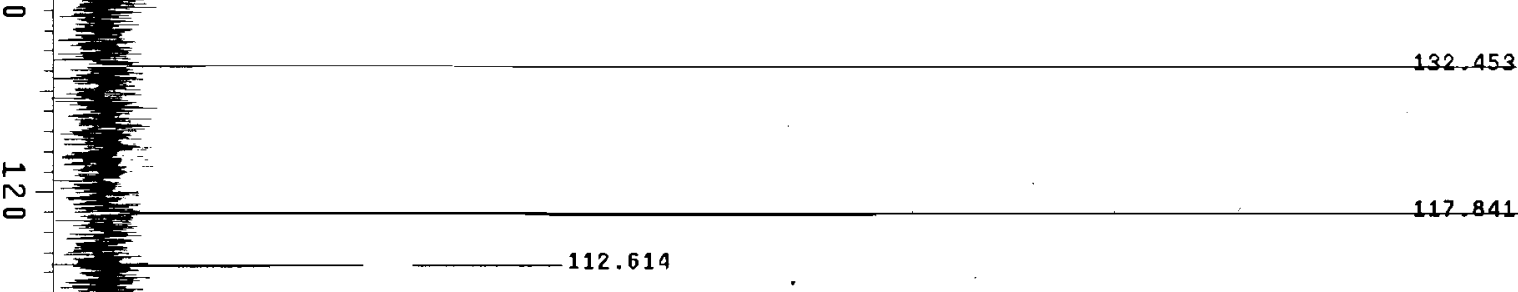

117.841

몽

$\stackrel{\infty}{\circ}$

a

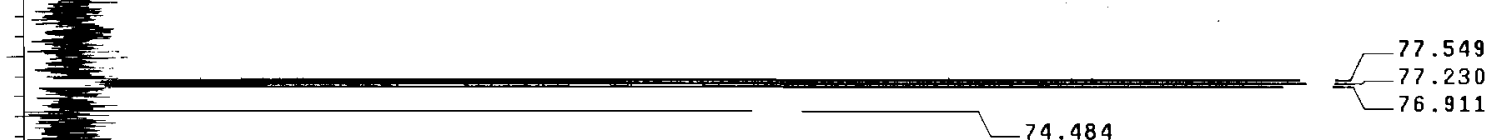

\&
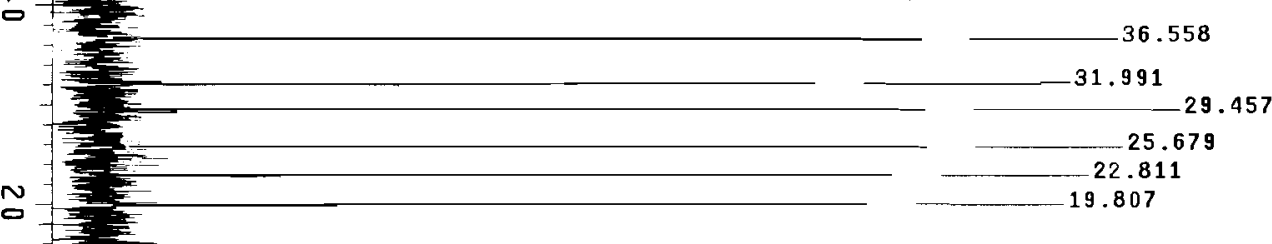

29.457

$-14.307$

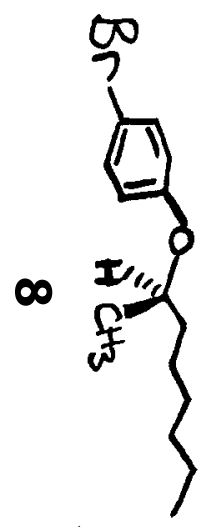

Wivition 


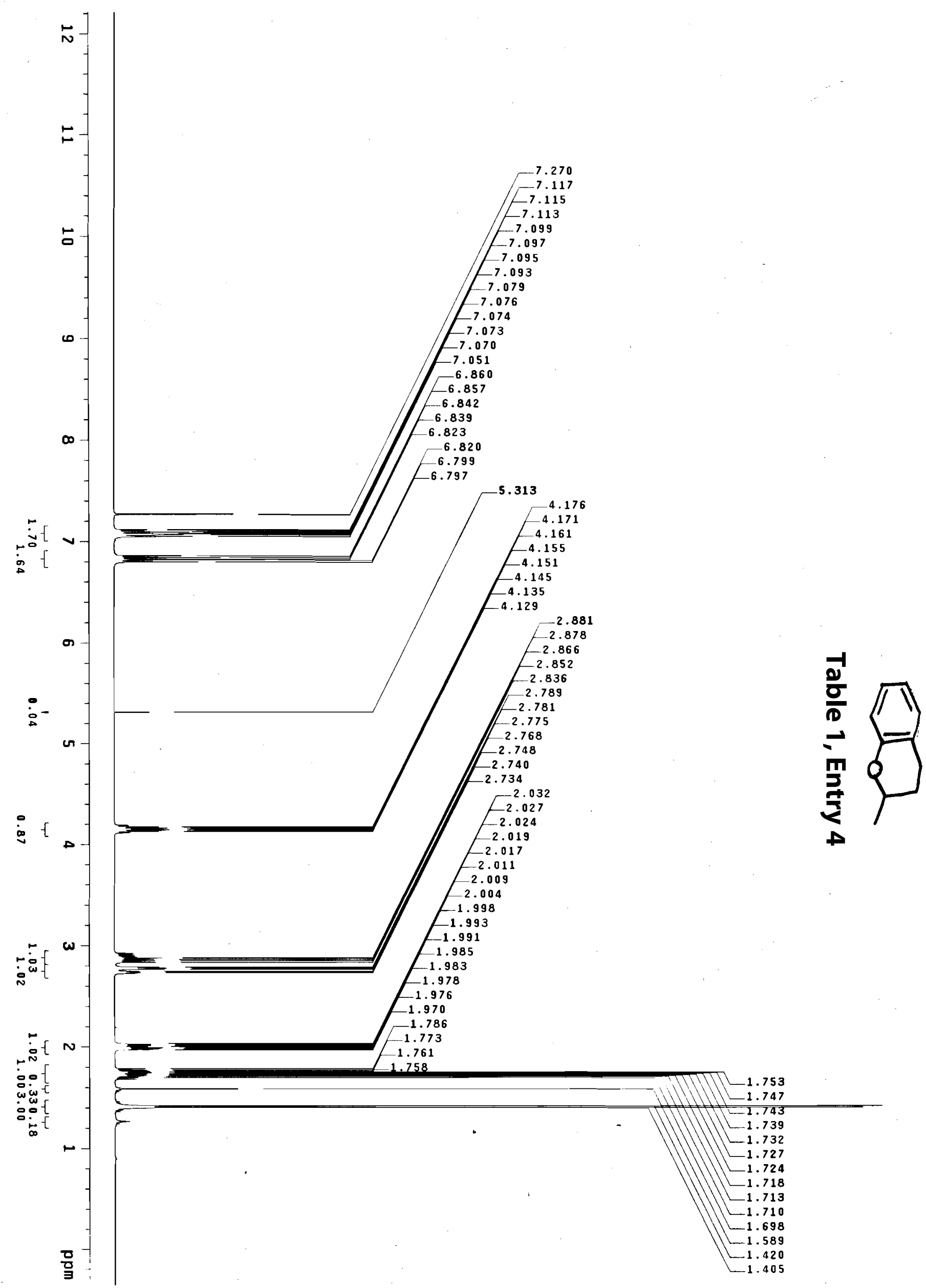



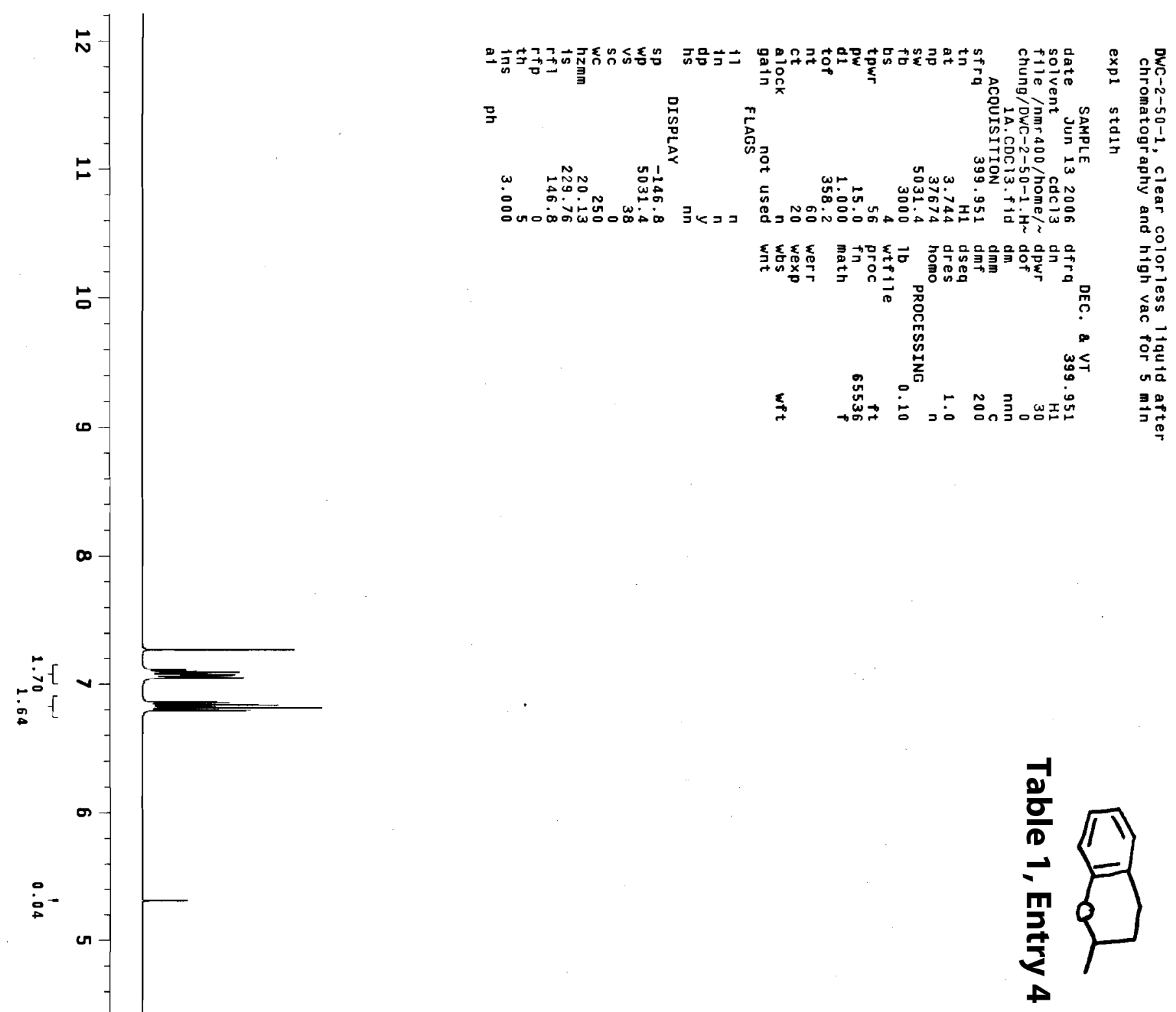


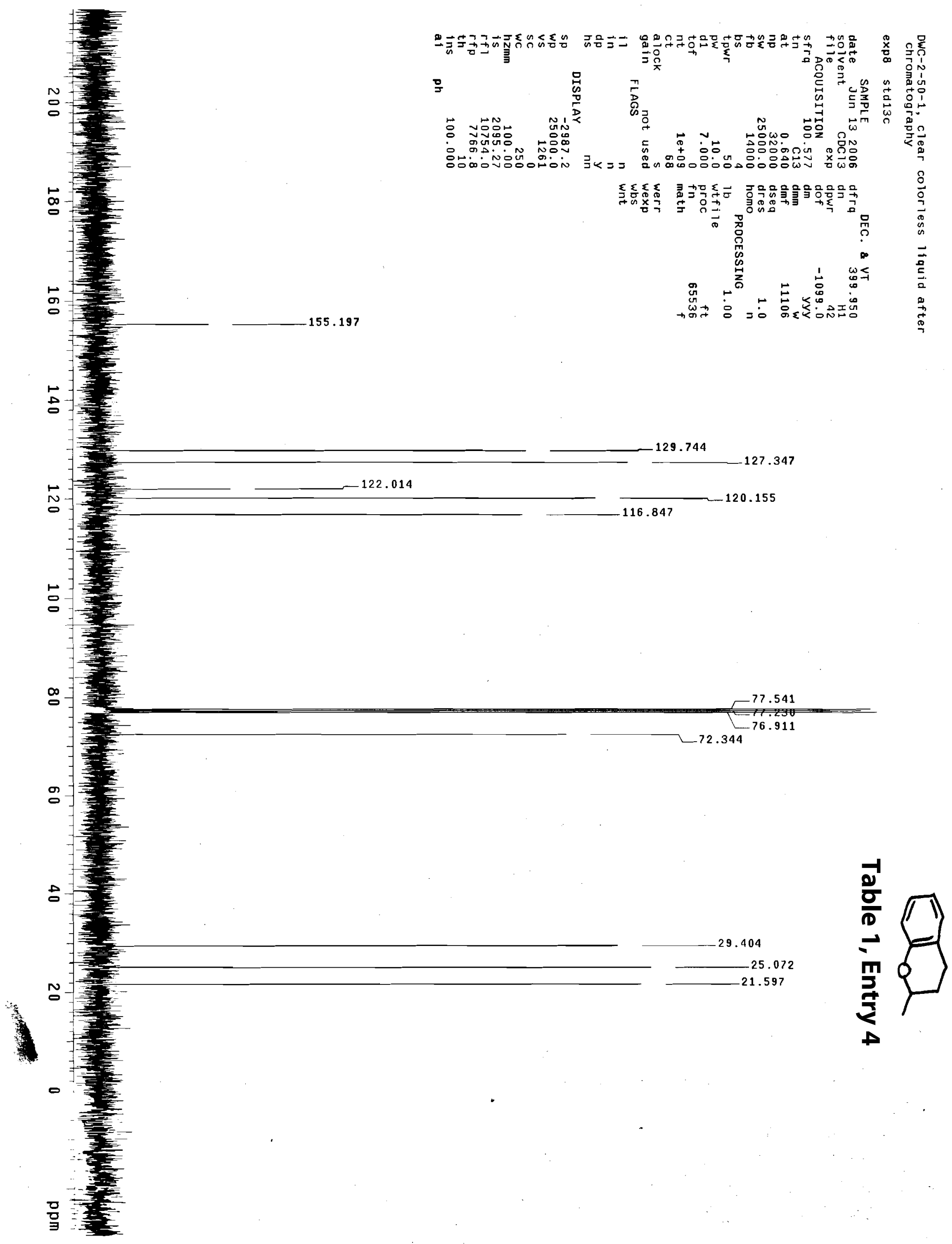



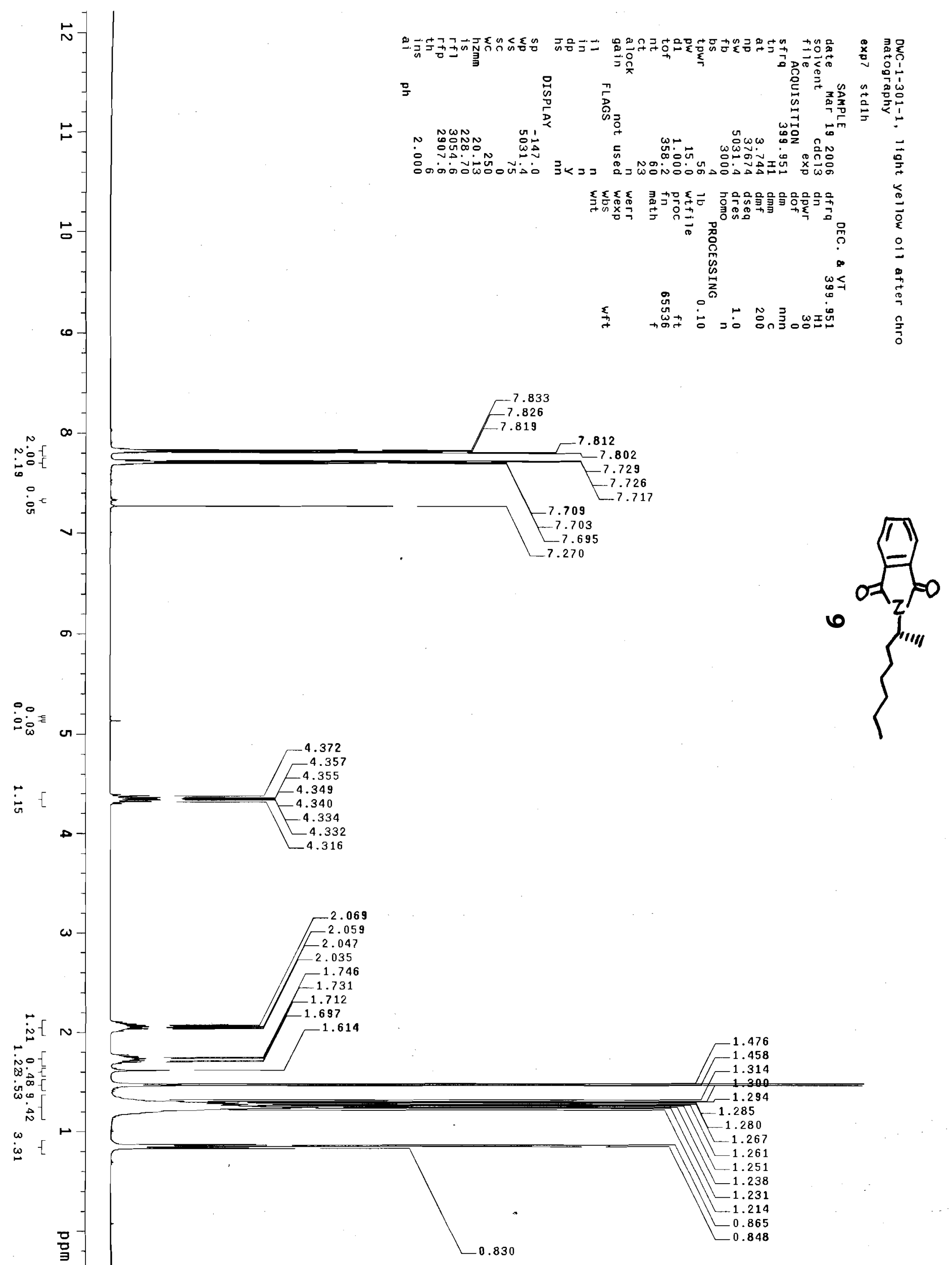

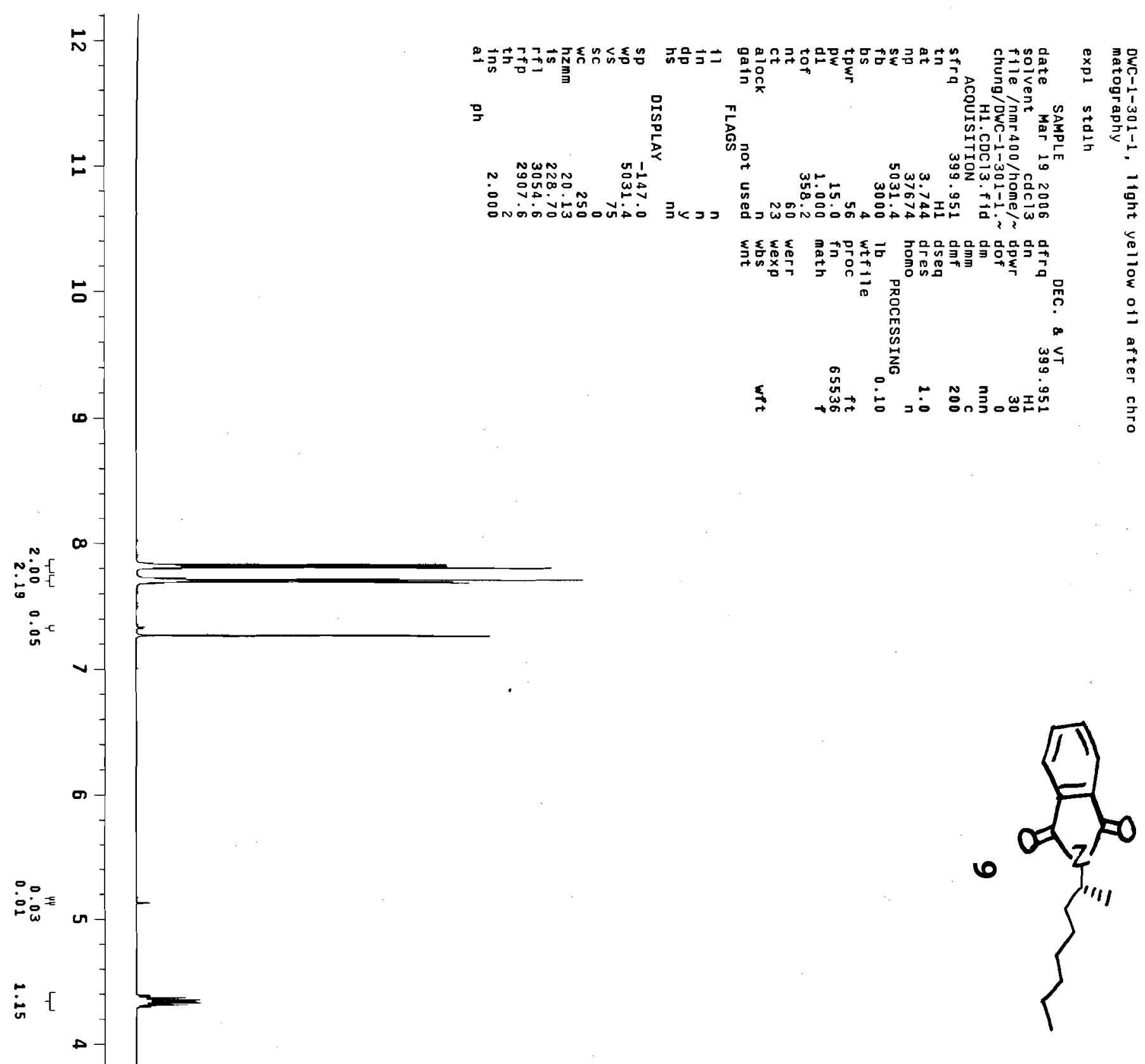

몰 


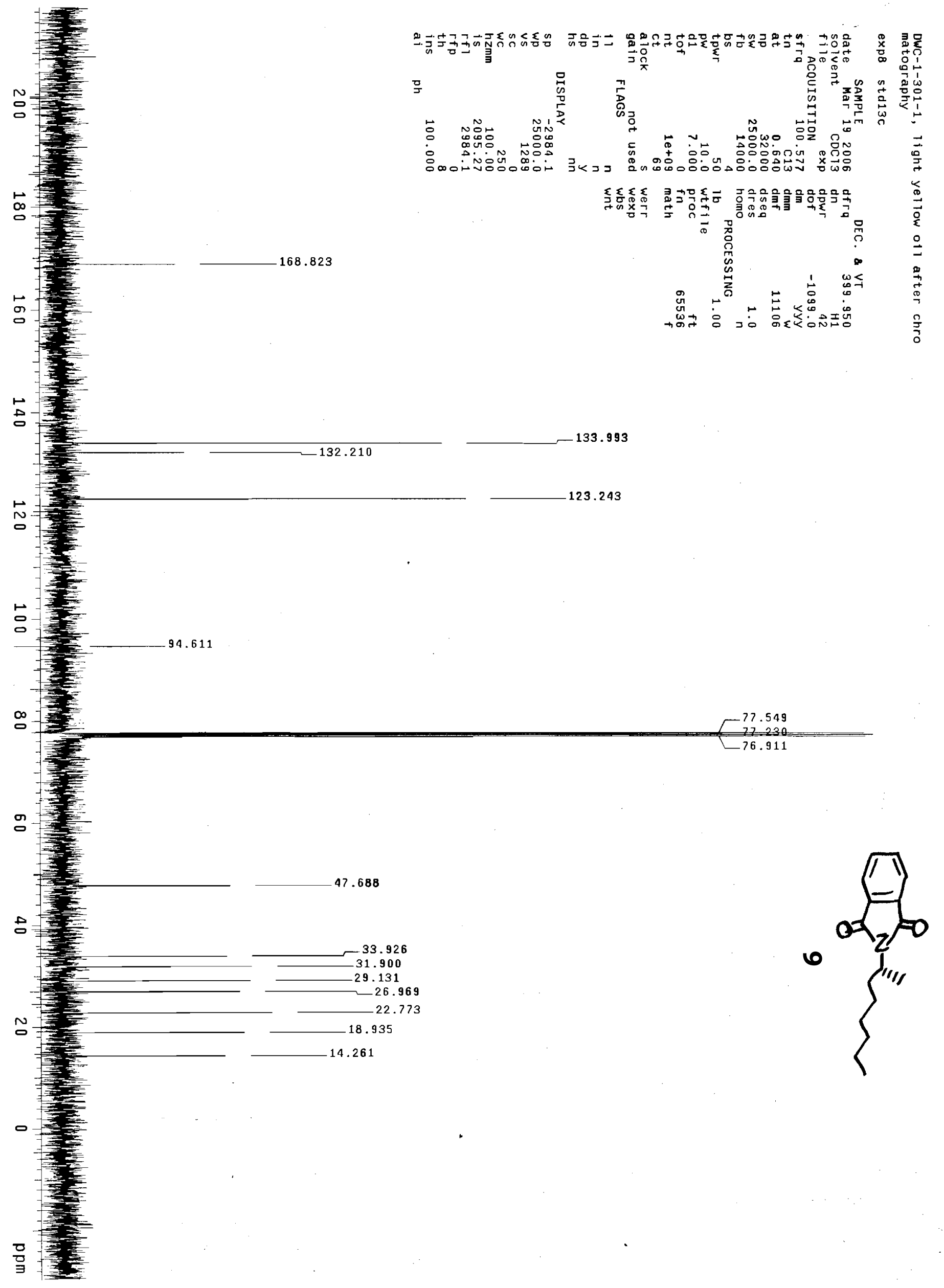




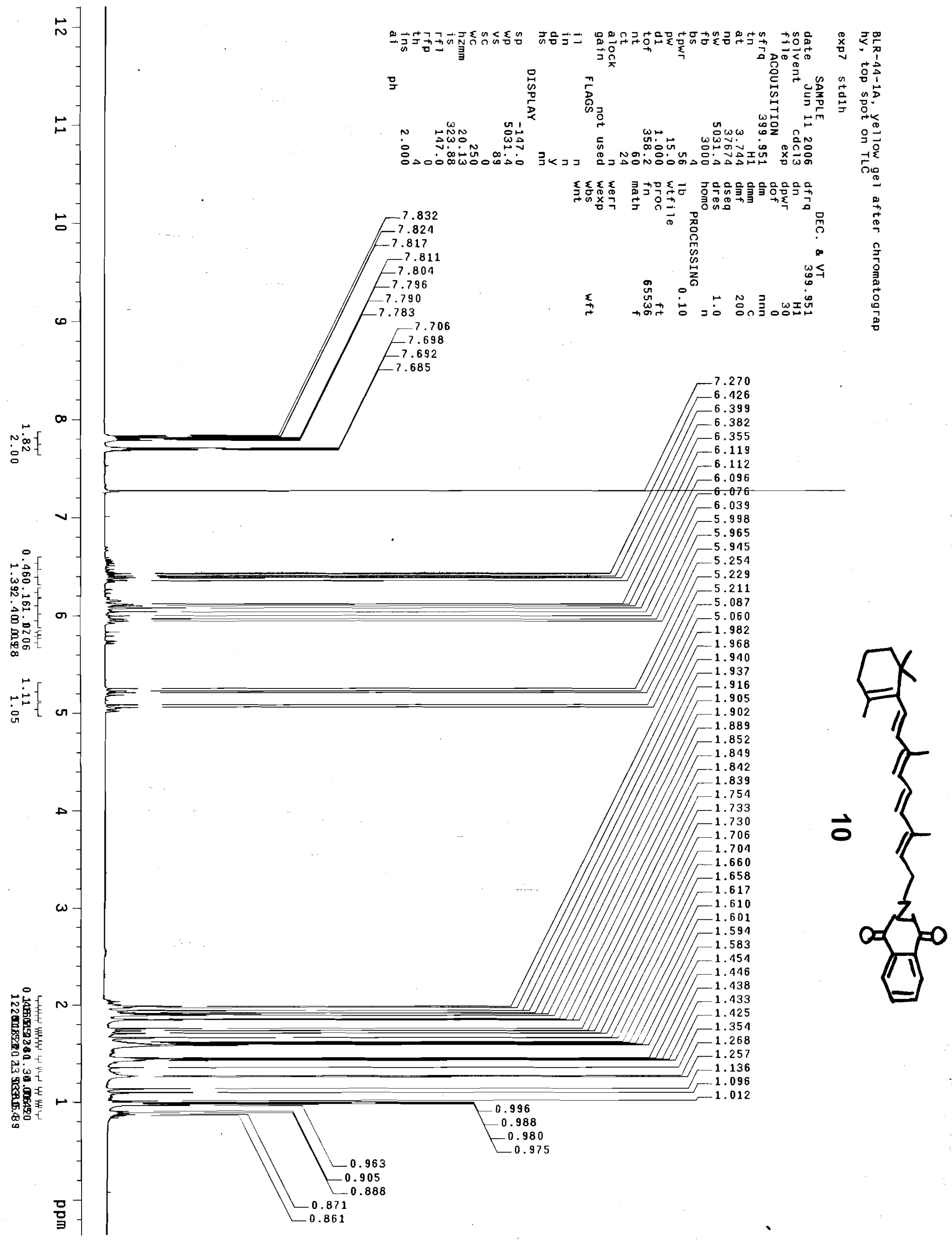




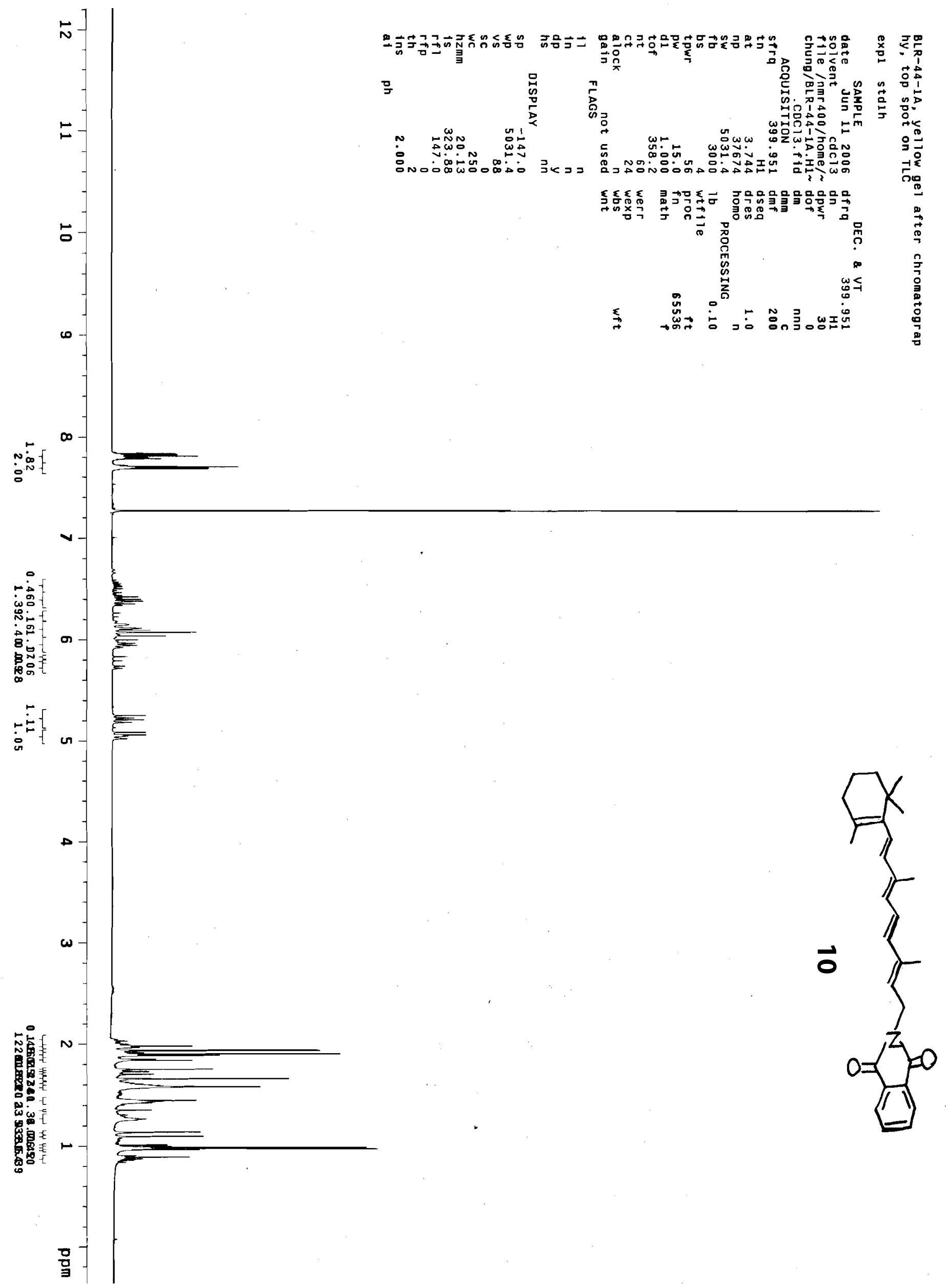




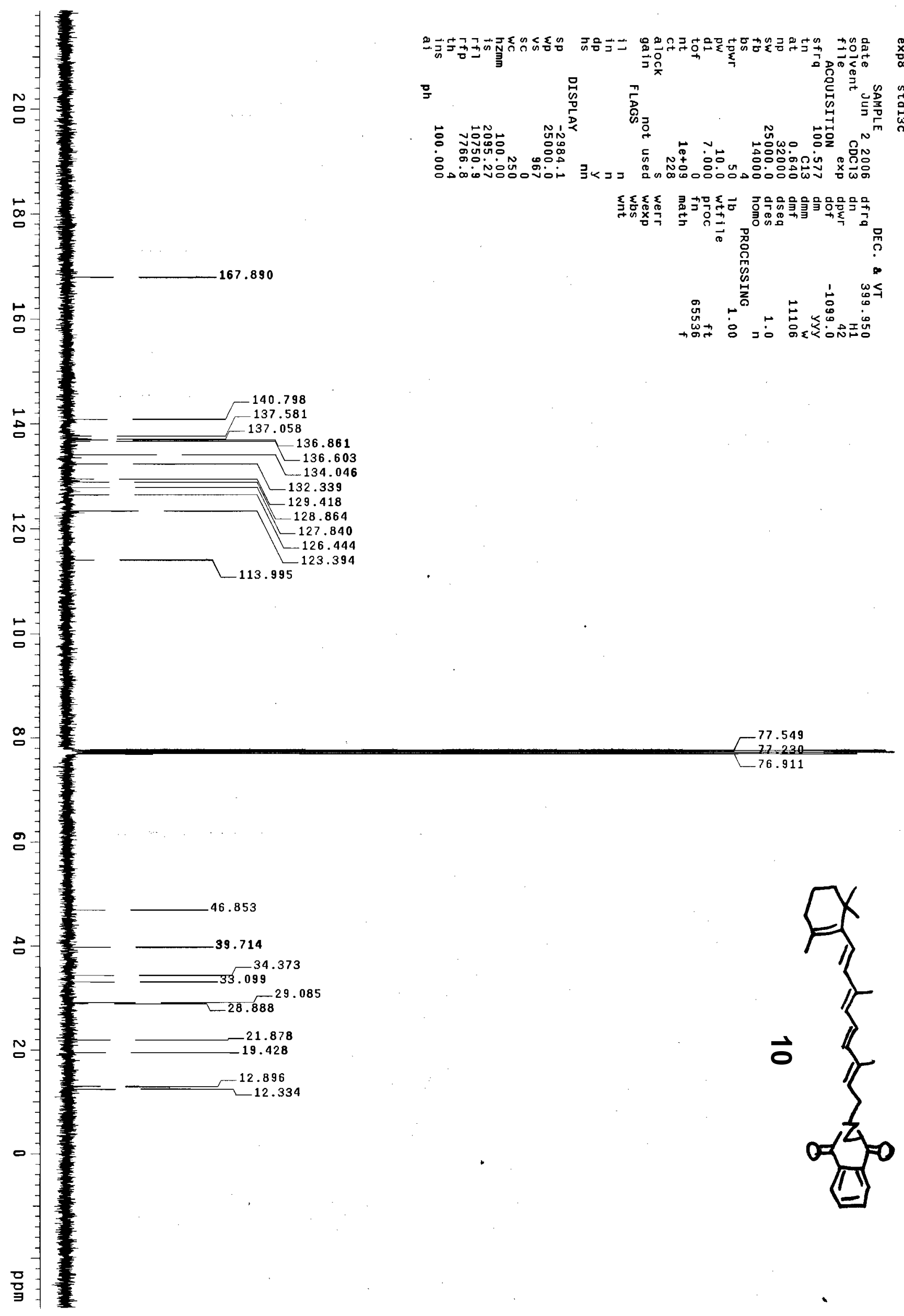




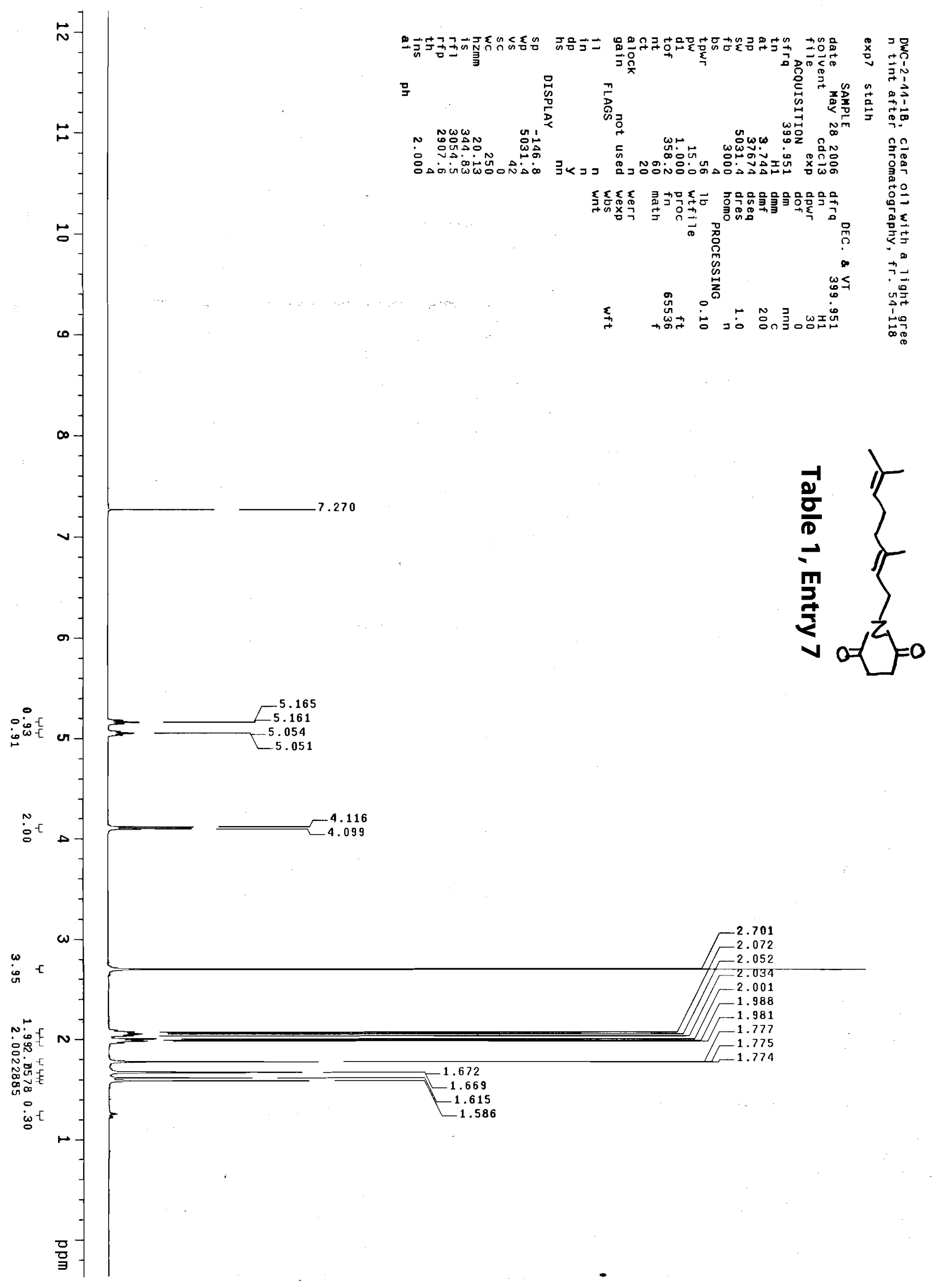

S31 


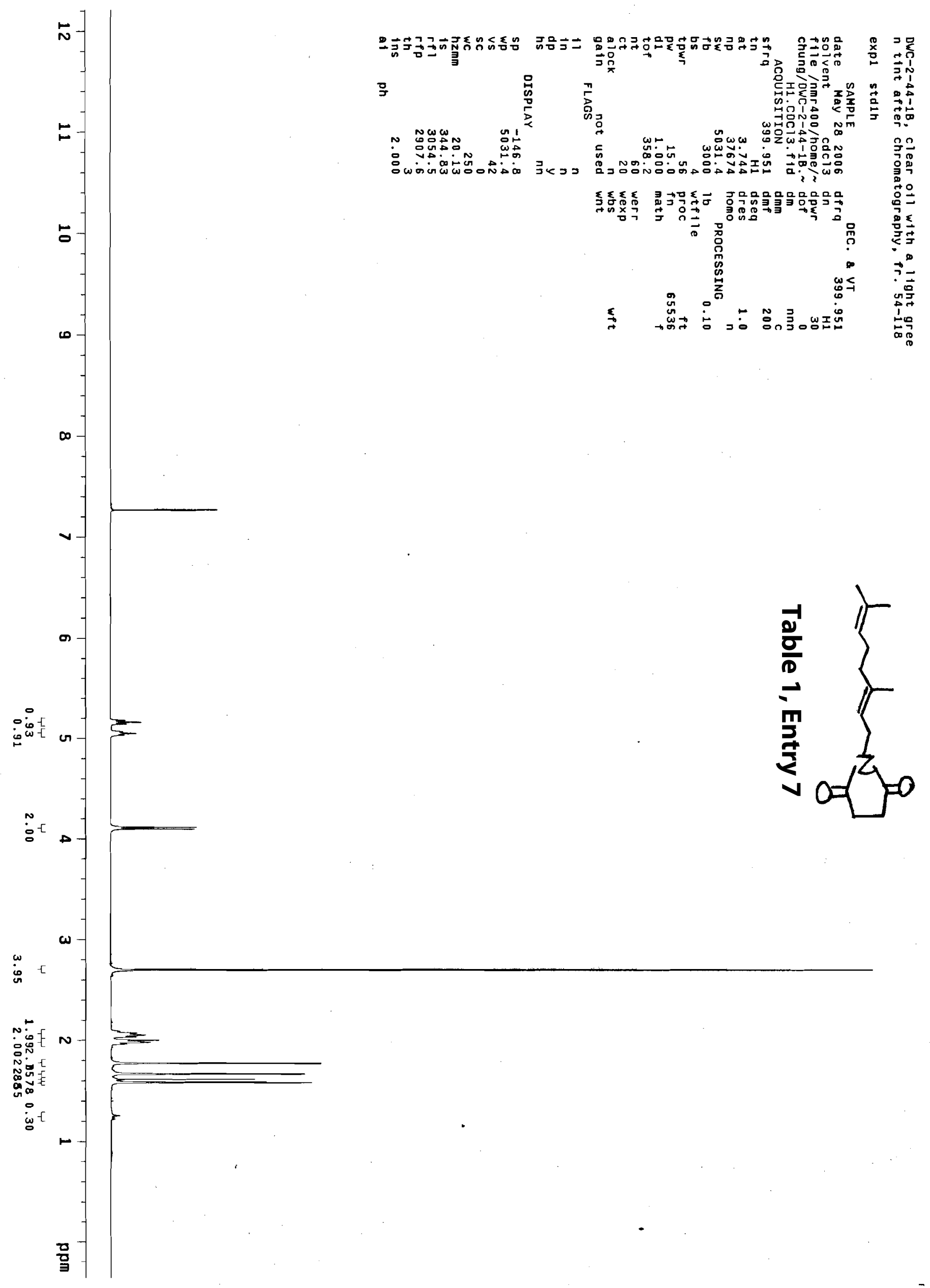




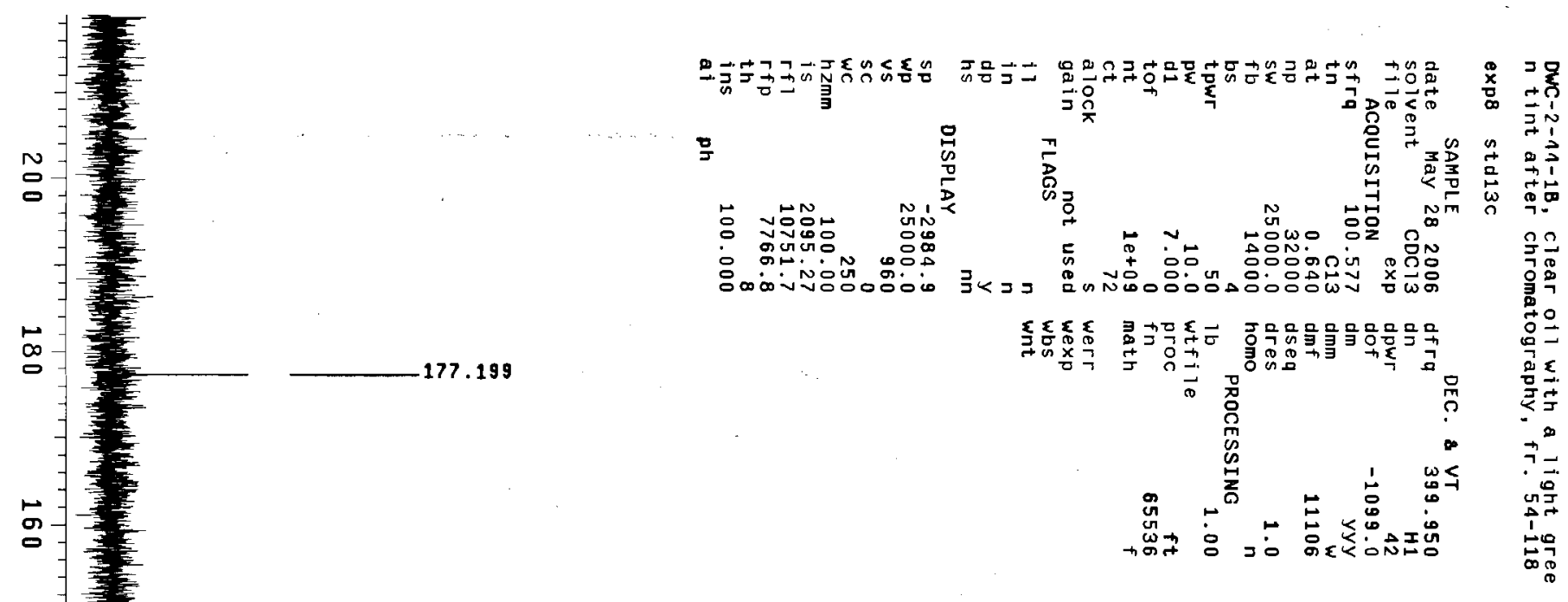

$\stackrel{\leftrightarrow}{\circ}$

芩

อ

$\infty$

141.238

131.952

123.979

117.356

g

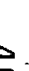

-
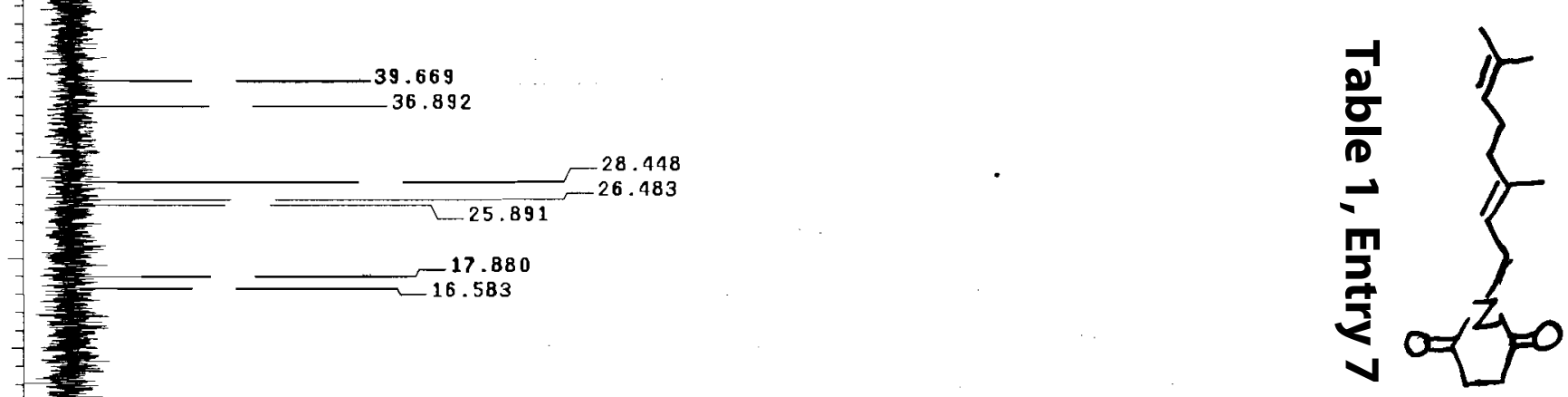

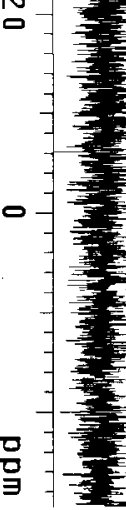

n-

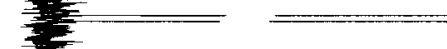

26.483 $+16.583$ 


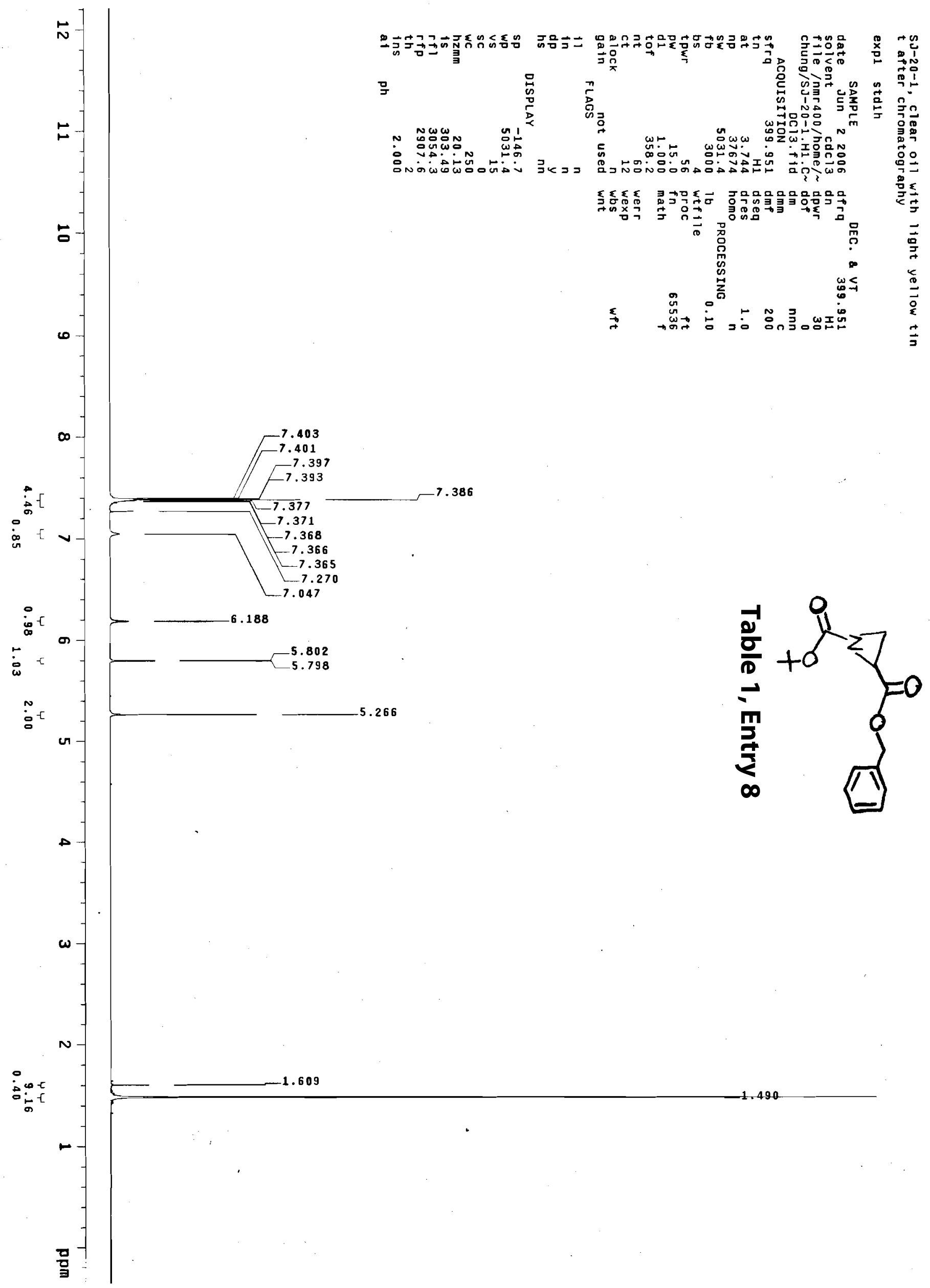




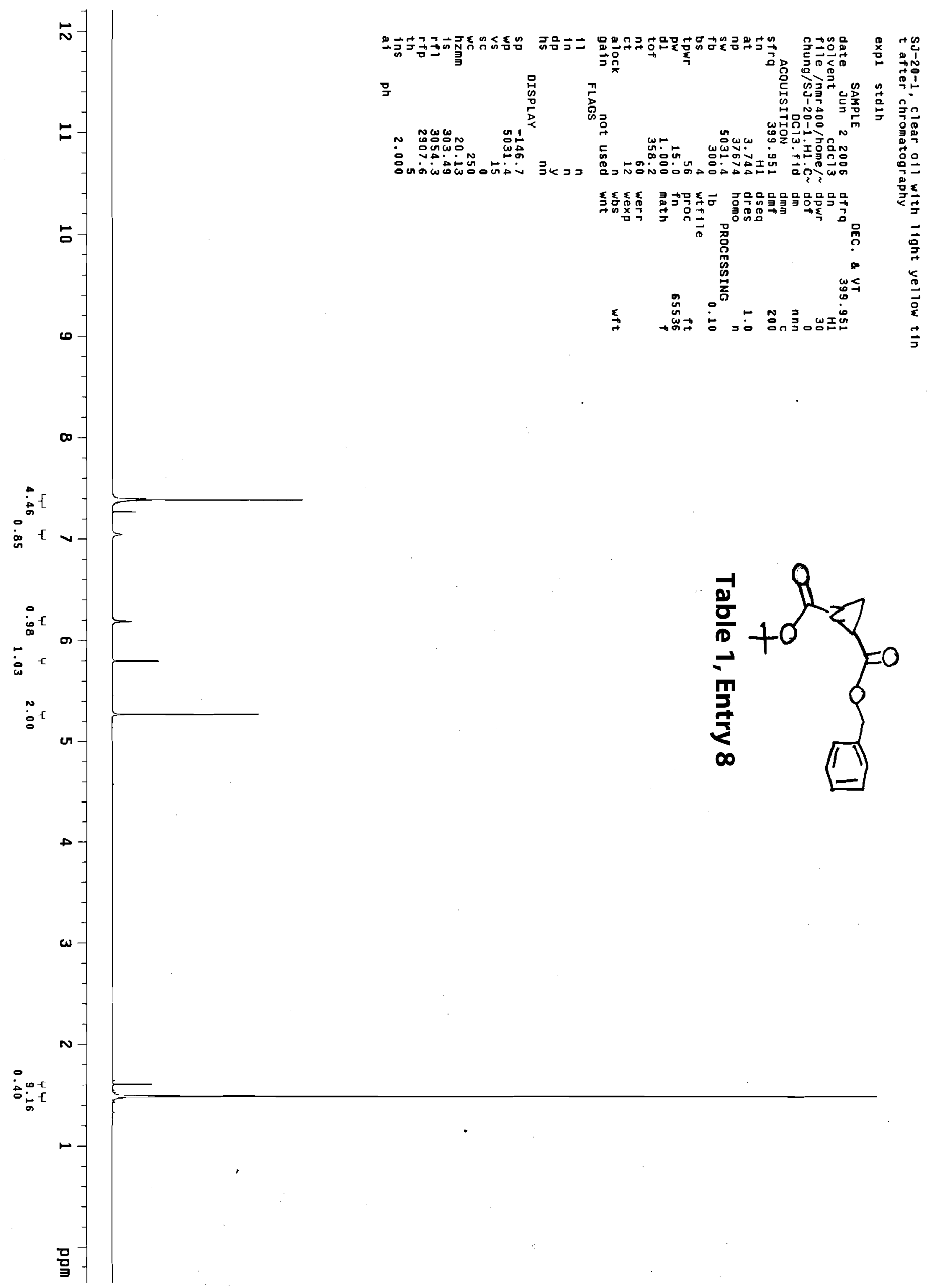




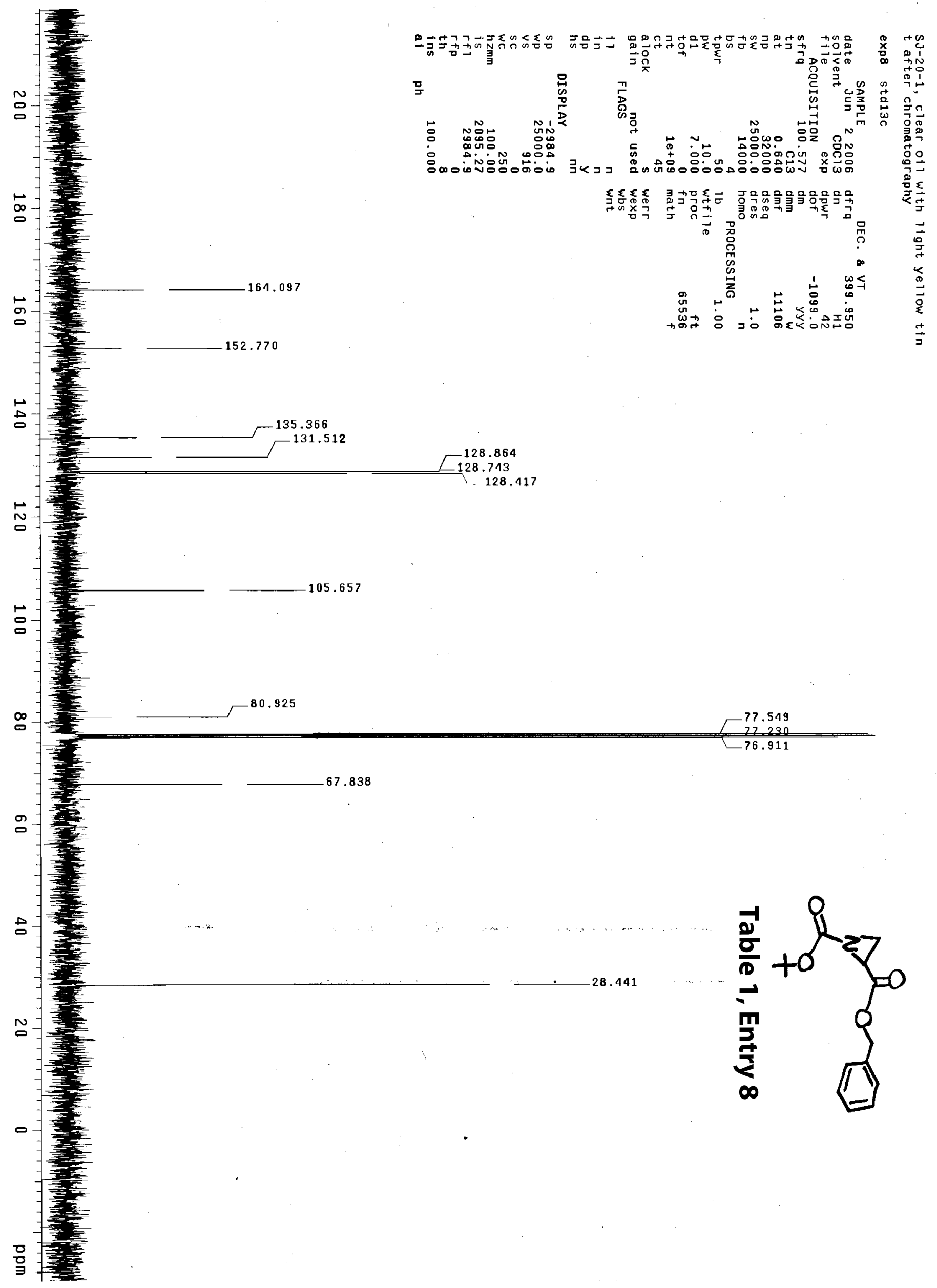




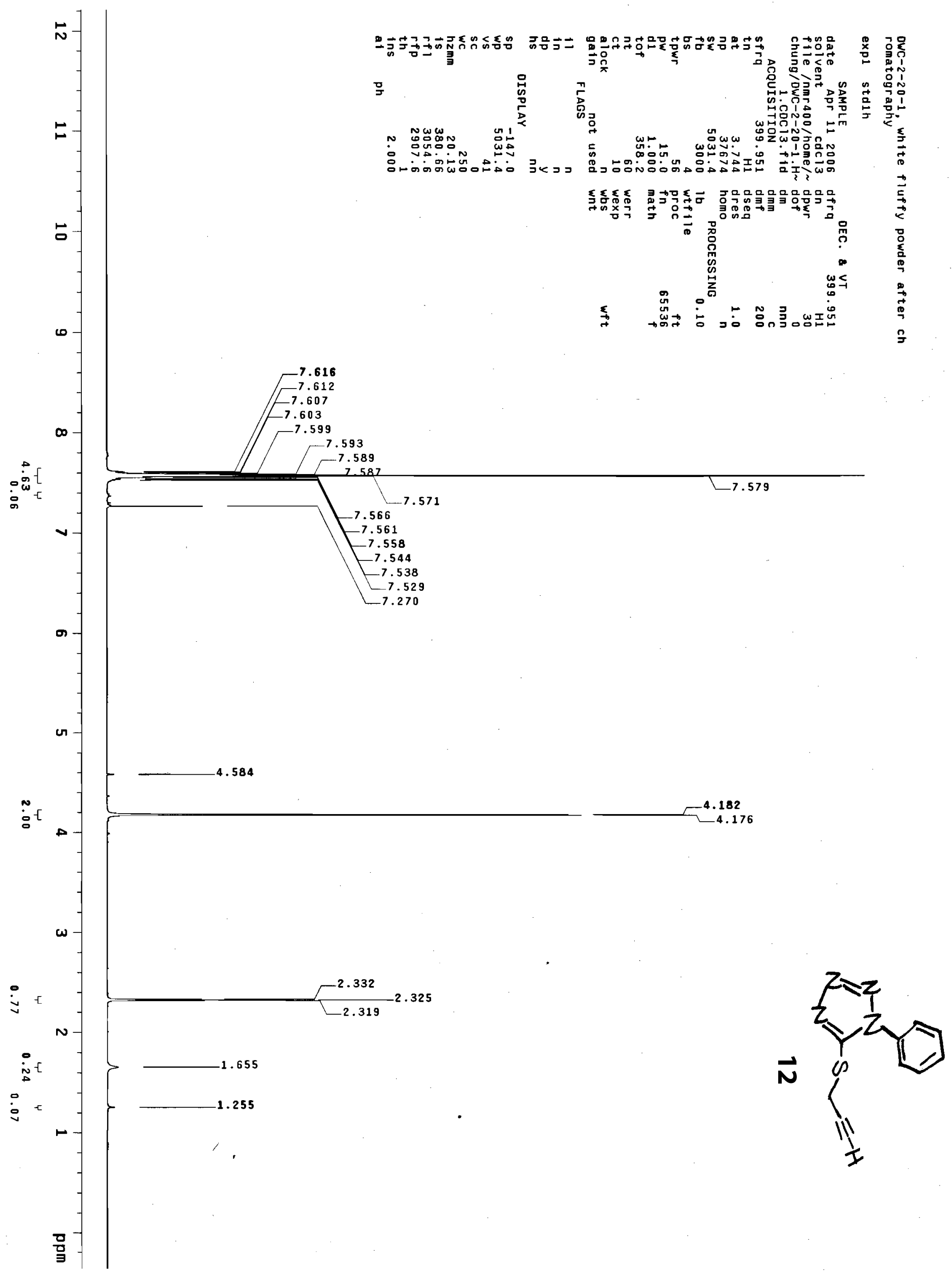




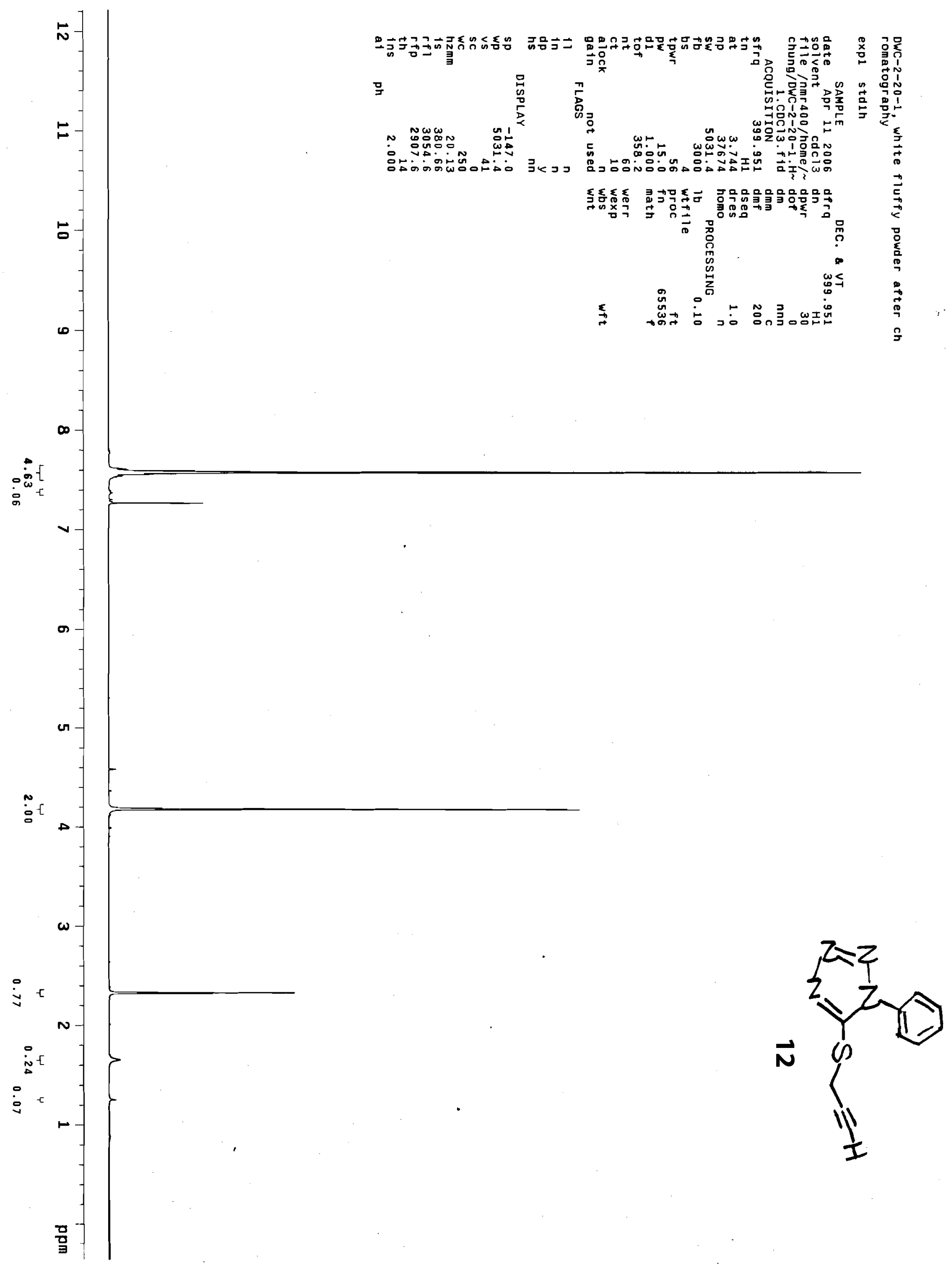




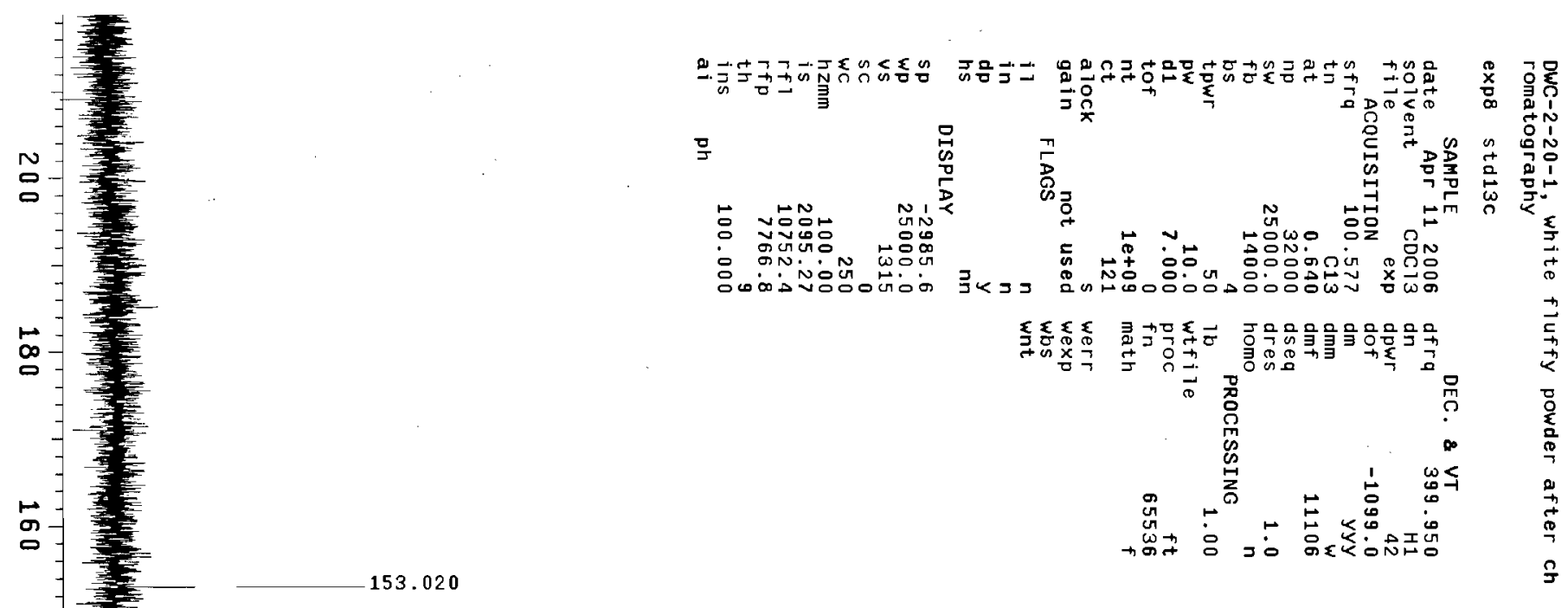

$\infty$ $-133.591$

$\stackrel{n}{0}$

吕 $-130.571$

음

-

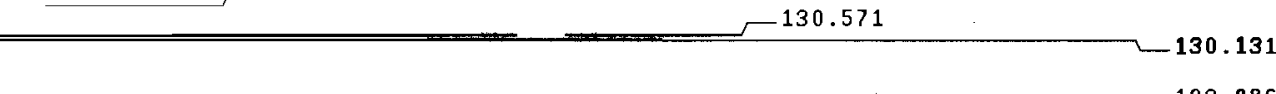

$\mapsto$

o

73.315

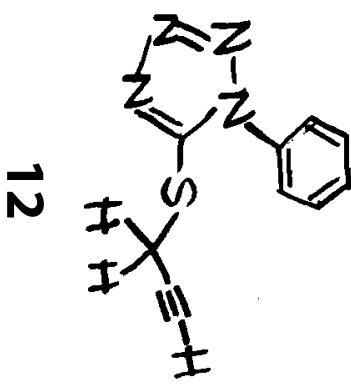

